\title{
Menin directs regionalized decidual transformation through epigenetically setting PTX3 as an obstacle balancing FGF and BMP signaling
}

Haibin Wang ( $\sim$ haibin.wang@vip.163.com)

Medical College of Xiamen University

Mengying Liu

Fujian Provincial Key Laboratory of Reproductive Health Research, School of Medicine, Xiamen

University

Wenbo Deng

Xiamen University https://orcid.org/0000-0001-7222-372X

Lu Tang

Xiamen University

Meng Liu

Xiamen University

Haili Bao

School of Medicine, Xiamen University

Chuanhui Guo

School of Medicine, Xiamen University

Chang Xian Zhang

Cancer Research Centre of Lyon https://orcid.org/0000-0002-5443-8951

Jinhua Lu

The First Affiliated Hospital of Xiamen University https://orcid.org/0000-0002-4164-4238

zhongxian Lu

xiamen university https://orcid.org/0000-0002-1682-7147

Shuangbo Kong

Fujian Provincial Key Laboratory of Reproductive Health Research, Medical College of Xiamen University

Article

Keywords: Men1, decidualization, H3K4me3, PTX3, pregnancy failure

Posted Date: September 3rd, 2021

DOI: https://doi.org/10.21203/rs.3.rs-839179/v1 
License: (c) (i) This work is licensed under a Creative Commons Attribution 4.0 International License. Read Full License

Version of Record: A version of this preprint was published at Nature Communications on February 22nd, 2022. See the published version at https://doi.org/10.1038/s41467-022-28657-2. 
1 Menin directs regionalized decidual transformation through

2 epigenetically setting PTX3 as an obstacle balancing FGF and BMP

3 signaling

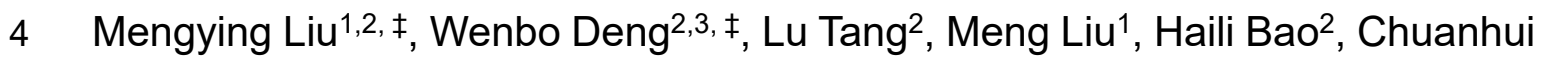

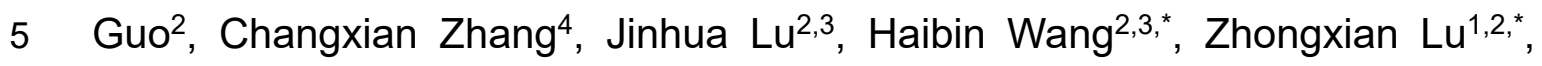

6 Shuangbo Kong ${ }^{2,3, *}$

7

8 1.School of Pharmaceutical Sciences, State Key Laboratory of Cellular Stress

9 Biology, Xiamen University, Xiamen, Fujian, China.

10 2.Fujian Provincial Key Laboratory of Reproductive Health Research, School of

11 Medicine, Xiamen University, Xiamen, Fujian, China.

12 3.Department of Obstetrics and Gynecology, The First Affiliated Hospital of 13 Xiamen University, Xiamen, Fujian, China.

14 4.Centre de Recherche en Cancérologie de Lyon, Inserm U1052, CNRS 15 UMR5286, Université Lyon 1, Lyon F-69000, France.

$17 \quad$ ‡Mengying Liu and Wenbo Deng contributed equally to this work.

19 *To whom correspondence may be addressed. Email:

20 haibin.wang@vip.163.com (H.W.), zhongxian@xmu.edu.cn (Z.L.) or

21 shuangbo_kong@163.com (S.K.). 


\section{Abstract}

During programmed decidualization in rodents, uterine stromal cells undergo extensive cellular and molecular reprograming into morphologically and functionally distinct decidual cells, forming the discrete regions defined as the primary decidual zone (PDZ), the secondary decidual zone (SDZ) and the layer of undifferentiated stromal cells respectively. However, the underlying mechanism governing this spatiotemporal specificity of decidualization remains elusive. Here, we demonstrated that uterine deletion of Men1, a key component of the MLL1/2 histone methyltransferase complex, disrupted the terminal differentiation of stromal cells, resulting in chaotic decidualization and pregnancy failure. Genome-wide epigenetic profile reveals that Men1 distribution in chromatin recapitulates the enrichment of transcription active modification $\mathrm{H} 3 \mathrm{~K} 4 \mathrm{me} 3$ orchestrating spatiotemporal decidualization of stromal cells. Further transcriptomic investigation demonstrates that Men1 directly regulated the expression of PTX3, an extra-cellular trap for FGF2, in a H3K4me3 dependent manner in decidual cells. Decreased Ptx3 upon Men1 ablation leads to aberrant activation of ERK1/2 in the SDZ due to the unrestrained FGF2 signal emanated from undifferentiated stromal cells, which blunt BMP2 induction and stromal cell differentiation during decidualization. In brief, our study provides genetic evidence and molecular mechanism for epigenetic rewiring mediated decidual regionalization by Men1 and shed new light in pregnancy maintenance. 
44 Key words: Men1, decidualization, H3K4me3, PTX3, pregnancy failure 


\section{Introduction}

(

Successful pregnancy requires rapid remodeling of the endometrium in a process termed decidualization, which requires the blastocyst attachment as a trigger and occurs in a region-specific manner in mice ${ }^{1}$. At the initiation of decidualization, stromal cells surrounding the implanted blastocyst undergo proliferation and postmitotic differentiation extensively, forming the primary decidual zone (PDZ) between day 5 (day 1= the day of positive of vaginal plug) and day $6^{2}$. Subsequently, stromal cells adjacent to the PDZ continue to proliferate and differentiate into decidual cells to form the secondary decidual zone (SDZ) at the antimesometrial pole by day 8 . A large portion of decidual cells experience polyploidization, characterized by large mono or bi-nucleated cells that undergo repeated DNA replication without cytokinesis ${ }^{3}$. In addition, a thin layer of undifferentiated stromal cells lines between the myometrium and the $\mathrm{SDZ}^{4}$. It is believed that the regionalized decidual structure is not only important for the supply of nutrition to the developing embryo but also acts as a barrier against excessive invasion of trophoblast cells ${ }^{1,5}$. While only small incrementation has made about the underlying mechanism directing programmed stromal cells differentiation in recent decades.

Several studies have demonstrated that a set of central genes in evolutionarily conserved signaling pathways during embryogenesis, such as BMP (bone morphogenetic protein), WNT (wingless-type MMTV integration site family), FGF (fibroblast growth factor) signaling and HOX (homeobox) genes, 
possess the potential function in building the regional pattern of decidualization ${ }^{4,6,7}$. BMP2, an indispensable factor for the differentiation of stromal cells into decidual cells, is intensively expressed in PDZ and SDZ6,8. The expression of WNT ligand Wnt4, which is also critical for the uterine stromal cell differentiation, largely overlapped with $B m p 2^{4}$. Meanwhile, Sfrp4, a WNT antagonist, is observed in the layer of undecidualized stromal cells outside the $\mathrm{SDZ}^{4}$. In addition to Sfrp4, Fgf2, a member of FGF family, also exhibits a similar expression pattern ${ }^{6}$. The fine-tuned interplay of these regionalization determinants synergistically or antagonistically promotes the tissue homeostasis during decidualization. However, how these genes are coordinated to specify the allocation of decidual cells remains largely unknown. Menin, encoded by the Men1, is a multifunctional scaffold protein participating in a variety of cellular functions, whose deficiency contributes to embryonic lethality at E11.5-E13.5 with defects in multiple organs ${ }^{9,10}$. Menin regulates target genes expression in a cell type-specific manner, including Hox genes, Cdkn1b and Cdkn2c, Esr1 and p35, by interacting with chromatinmodifying enzymes, in particular, the histone methyltransferase (HMT) MLL1/2 that catalyze histone 3 lysine 4 trimethylation $(\mathrm{H} 3 \mathrm{~K} 4 \mathrm{me} 3)^{11-15}$. Regarding that early pregnancy is a precisely regulated process, whether the target genes of Menin-MLL complex and how Menin and its interplay with H3K4me3 modification participate in embryo implantation and decidualization remain elusive. 

pharmacological approaches to investigate the role of Men1 in peri-implantation

91 uteri and reveal that Men1 ablation disrupts the appropriated differentiation of

92 decidual stromal cells, resulting in unordered regionalization of decidualization 93 and compromised pregnancy success. The reduction of Bmp2 caused by 94 aberrantly activated FGF2-ERK1/2 signaling pathway deranges the adequate 95 development of the SDZ due to disorganized genomic H3K4me3 modification 96 in the absence of Men1. The previously unappreciated PTX3, an extra-cellular 97 protein trapping FGF2, is identified as a Menin directly regulated downstream 98 gene and provides insightful information for the orchestration of decidualization 99 and pregnancy maintenance in curbing the cross-talk between FGF2-ERK1/2 100 and BMP2. 


\section{Results}

Men1 is expressed in the peri-implantation mouse uterus in a spatiotemporal manner

Highly heterogeneous uterine endometrium is comprised with different cell types that undergo tremendous changes during early pregnancy. To elucidate the physiological significance of Men1 during early pregnancy, we first examined the cell-specific and temporal expression of Men1 in periimplantation uteri using in situ hybridization. There was weak Men1 expression in pre-implantation uterus on days 1 and 4. After embryo implantation, Men1 transcript was moderately up-regulated in proliferating stromal cells surrounding the blastocyst on day 5. Accompanied by the initiation of decidualization, stromal cells underlying the implantation chamber exit mitosis and differentiate into epithelioid cells to form the PDZ. The transcript of Men1 became undetectable in the PDZ but was intensively expressed in proliferating stromal cells outside the PDZ on day 6. After the SDZ was established by day 8, Men1 expression was restricted in mesometrial pole (Fig. 1a). These observations indicated that Men1 expression was tightly correlated with the progress of decidualization. Consistent with its mRNA expression pattern, Menin protein was widely expressed in the uterus during decidualization and located mainly in nucleus (Fig 1b). It was interesting to note that Menin protein possessed wider expression than its transcript which perhaps due to the discrepant stability between mRNA and protein. Account for the well 
overlapping between Men1 mRNA and proliferating cells, it was conceivable to speculate that the newly transcribed Men1 was probably for Men1 translation for daughter cells during mitosis (Fig 1b). The spatiotemporal expression pattern of Men1 indicates that it could be a considerable regulator in periimplantation events.

\section{Mice with uterine deletion of Men1 show severe subfertility}

To explore the functional role of uterine Men1 in pregnancy, we generated mice with uterine deletion of Men1(Men $\left.1^{\mathrm{d} / \mathrm{d}}\right)$ by crossing Men1 floxed mice $\left(M e n 1^{f / f}\right)$ with PR-Cre mice $\left(P g r^{C r e /+}\right)^{10,16}$. These mice show efficient deletion of Men1 in the pregnant uterus at both mRNA and protein levels (Fig. 1c-e). To interrogate the role of Men1 in female fertility, Men $1^{\mathrm{d} / \mathrm{d}}$ mice and their littermate controls $\left(M e n 1^{\mathrm{f} / \mathrm{f}}\right)$ were mated with wild type fertile males. Only $25 \%$ plugpositive Men $1^{\mathrm{d} / \mathrm{d}}$ mice gave birth to offspring and the litter size was significantly lower than those in littermate Men1/f mice (Fig. 1f, g). These results demonstrated uterine Men1 was crucial for successful pregnancy.

\section{Ablation of uterine Men1 causes defective decidualization and miscarriage at mid-gestation}

Early pregnancy is a highly programmed dynamic process involving blastocyst attachment, decidualization and placentation. Defects at any stage will give rise to adverse pregnancy outcomes. To dissect out the defects causing 
subfertility in Men1 $1^{\mathrm{d} / \mathrm{d}}$ mice, we first assessed the early pregnancy events on day 5 with increased vascular permeability at the attachment site ${ }^{17}$. The number of implantation sites and the embryo spacing were comparable in Men $1^{\text {f/f }}$ and Men $1^{\mathrm{d} / \mathrm{d}}$ mice on day 5 as visualized by intravenous injection of Chicago blue (Fig. 2a, b). The gross morphology and embryo attachment reaction as revealed by HE staining and COX2 expression, respectively, were also similar between

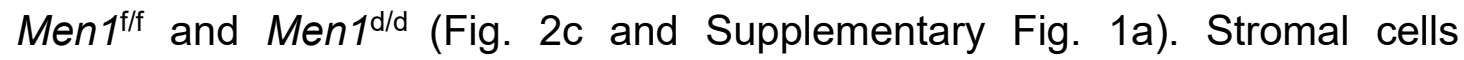
surrounding the blastocyst undergo extensive proliferation and differentiation into decidual cells under the initiation of $\mathrm{BMP}^{2,8}$. The semblable proliferation and expression pattern of Bmp2 and BMP antagonist Dan in Men1/f and Men $1^{\mathrm{d} / \mathrm{d}}$ implantation sites confirmed that mice with uterine deletion of Men1 had normal initiation of decidualization (Fig. 2d and Supplementary Fig. 1b-d). Moreover, IGFBP5, which provide a favorable environment for blastocyst growth by coupling with IGF $1^{18}$, had a similar subepithelial expression pattern in Men $1^{\mathrm{f} / \mathrm{f}}$ and Men $1^{\mathrm{d} / \mathrm{d}}$ implantation sites (Supplementary Fig. 1e).

Since the deficiency of Men1 has no severe defects in the blastocyst attachment reaction and the initiation of decidualization, we next examined the progress of decidualization. The morphology of decidual bulge and the number of implantation sites were comparable between $M e n 1^{\mathrm{f} / \mathrm{f}}$ and $M e n 1^{\mathrm{d} / \mathrm{d}}$ mice on day 6 with termination of stromal cell proliferation in the established PDZ (Fig. 2e, f and Supplementary Fig. 2a). Our results showed that there were comparable expressions of OCT4, Ki67, Dtprp, COX2, Bmp7, $\beta$-Catenin and 
Wnt4 in day 6 uteri, implying normal embryo development, stromal cell proliferation, PDZ formation ${ }^{19-22}$ (Supplementary Fig. 2b-h). Collectively, these results indicated that uterine Men1 was dispensable for blastocyst attachment and PDZ formation.

Following the formation of PDZ, stromal cells adjacent to the PDZ continue to proliferate and differentiate to form SDZ until day 8. Reduced average weight of implantation sites with retarded embryos was emerged in Men1/d/d mice on day 8 in comparison to Men $1^{1 / f}$ mice (Fig. $2 \mathrm{~g}-\mathrm{i}$ ). From day 9 to day 12 , more obvious defects appeared at the implantation sites, including abnormal placentation and severe embryo absorption (Fig. 2j-I). These data hinted that the formation of SDZ was hindered from day 7 to day 8 . In order to further confirm the effect of Men1 deletion on the progress of decidualization, an oilinduced artificial decidualization mode ${ }^{23}$ was applied (Supplementary Fig. 3a). Men $1^{\text {f/f }}$ mice uteri exhibited a robust decidual response 96 hours after intraluminal oil injection, while the Men $1^{\mathrm{d} / \mathrm{d}}$ uteri showed a remarkably weakened or disappeared decidual response (Supplementary Fig. 3b, c). Collectively, these results demonstrated that uterine specific deletion of Men1 disturbed the progression of decidualization and ultimately resulted in embryo resorption and miscarriage at mid-gestation. 

the cellular defects in Men1/d $1^{\mathrm{d} d}$ uteri. Polyploidization, a hallmark of mature

191 decidual cells in the SDZ, was marked by mono or bi-nucleated cells through 192 endoduplication. H3K27me3 was critical epigenetic modification for $\mathrm{X}$ 193 chromosome inactivation for dose complementary effect of female somatic 194 cells $^{24}$. Our results showed that polyploid decidual cells in Men1/f mice 195 possessed more than four puncta H3K27me3 staining, indicating at least four 196 sets of homologous chromosomes in polyploid decidual cells. While the number 197 of polyploid decidual cells was obviously reduced in Men $1^{\mathrm{d} / \mathrm{d}}$ mice (Fig. 3a, b). 198 Consistently, we found aberrantly increased PCNA (DNA replication in S-phase) and BrdU (DNA synthesis in S-phase) in Men1 ${ }^{\mathrm{d} / \mathrm{d}}$ decidual cells on day 7.5 of pregnancy (Fig. 3b). Further, flow cytometric analysis of DNA content revealed 201 that $2 \mathrm{~N}$ cells were significantly increased with a concomitant decreased of $>4 \mathrm{~N}$ 202 cells in Men1 deletion decidual tissues on day 8 (Fig. 3c, d). In Men1/d/ mice, 203 both Dtprp mRNA and protein were significantly reduced on day 8 (Fig. 3e, f), 204 suggesting that the terminal differentiation of decidual cells was impaired. 205 These results indicated Men1 was critical for the progression of polyploidy 206 during decidualization. was disordered, foreboding impaired placentation in Men1/d mice (Fig. 3g, h). 209 Accompanied by normal decidualization, abundant uterine natural killer (uNK) 210 cells accumulated at the mesometrial pole on day $8^{25}$. In contrast to numerous 
$211 \mathrm{DBA}^{+}$uNK cells in Men1/f mesometrial pole, Men1 null uteri exhibited dramatic 212 decrease of uNK cells (Fig. 3h). Aberrant decidualization tends to give rise to 213 abnormal trophoblast invasion and compromised placentation ${ }^{5}$. Eccentric 214 expression pattern of trophoblast giant cells marker PL1 in Men $1^{\mathrm{d} / \mathrm{d}}$ uteri 215 signified shallow trophoblast invasion on day 8 (Fig. 3i). All these observations 216 strongly proved the defective decidualization in the absence of uterine Men1.

217 The morphological and physiological changes of stromal cells during 218 decidualization is mainly regulated by steroid hormones from ovary ${ }^{1}$. 219 Progesterone is indispensable for decidualization maintenance through its cognate nuclear receptor progesterone receptor $(P R)^{5}$. There was no significant 221 difference in circulating levels of E2 and P4 in both groups on day 6 with similar 222 expression of progesterone biosynthetic enzymes cytochrome P450 223 cholesterol side-chain cleavage enzyme (P450scc) and 3 $\beta$-hydroxysteroid 224 dehydrogenase (3ß-HSD) in the ovary as well as comparable expression PR 225 and its target genes, Hand2 and Hoxa10, in day 6 and day 8 uterus 226 (Supplementary Fig. 4a, b and Supplementary Fig. 5a-f). These data suggested 227 that the defect decidualization was primary originated from local dysfunction of 228 Men1 in stromal cells. Men1 To further excavate the underlying molecular mechanism for the defective 
terminal differentiation of decidual cells in the SDZ observed in Men1 ${ }^{\mathrm{d} / \mathrm{d}}$ mice,

234 decidual tissues were isolated from Men $1^{\mathrm{flf}}$ and Men $1^{\mathrm{d} / \mathrm{d}}$ uteri on day 8 and 235 subjected to gene expression profiles analysis using RNA sequencing (RNA236 seq). A total of 1,669 genes were differential expressed with 870 down237 regulated genes (Supplementary Data 1) and 789 up-regulated genes 238 (Supplementary Data 2) in Men $1^{\mathrm{d} / \mathrm{d}}$ mice in comparison to wild type (Fig. 4a). 239 Decidualization involves a series of biological changes including the 240 proliferation and differentiation of stromal cells, angiogenesis and 241 immunological adaptation $5,22,26$. Functional annotation revealed that down242 regulated genes upon Men1 deletion mainly enriched in the terms of cell 243 proliferation inhibition, fatty acid metabolic process, multicellular organism 244 development and negative regulation of angiogenesis (Fig. $4 \mathrm{~b}$ and 245 Supplementary Data 3). In contrast, genes up-regulated in Men1 ${ }^{\mathrm{d} / \mathrm{d}}$ decidual 246 tissues were enriched in categories that were resistance to cell differentiation 247 such as positive regulation of ERK1/2 cascade and categories detrimental to 248 the development of decidua such as apoptotic process and inflammatory 249 response (Fig. 4b and Supplementary Data 4).

250 The down-regulated genes in negative regulation of cell proliferation, 251 including Bmp2, Ptn, Fgf10 and Igf1, possessed specific expression patterns 252 and were important for decidualization ${ }^{6,27,28}$ (Fig. 4c, d). On the contrary, genes 253 associated with the activation of MAPK activity that promotes cell proliferation 254 (Fgfr1, Pdgfa) were up-regulated in Men1 ${ }^{\mathrm{d} / \mathrm{d}}$ uteri (Fig. 4c). Besides, genes 
expressed in the thin layer of undecidualized stromal cells were increased after

Men1 knockout, such as Sfrp4 and PrIr (Fig. 4c, d).

Increased vascular permeability and angiogenesis are crucial to successful

decidualization. Angiopoietins (ANGPT1 and ANGPT2) and their receptor TIE2

directs angiogenesis during decidualization ${ }^{22,26}$. ANGPT1 induces vessel

maturation and maintains vessel leakiness, whereas ANGPT2, acting as a

261 natural antagonist of ANGPT1, induces vessel destabilization required for

262 further sprouting and regression of vessels ${ }^{29}$. Our RNA-seq data indicated

263 several genes in promoting angiogenesis (Angpt1, Edn1, Ednra) were up-

264 regulated and genes in inducing destabilization of blood vessels and endothelial

265 sprouting (Angpt2, Hif3a, Mmp2) were down-regulated due to uterine Men1

266 deletion (Fig. 4c, e). Furthermore, NK-specific genes (Prf1, Klrg1, Ctsg, I/15r)

267 and several granzyme genes (Gzma, Gzmb, Gzmc, Gzmd, Gzme, Gzmg) were

268 significantly decreased in Men1/d decidua (Fig. 4c), indicating the maturation

269 of uNK was compromised. Moreover, Corin, functions in promoting trophoblast

270 invasion and spiral artery remodeling ${ }^{30}$, was decreased substantially in Men $1^{\mathrm{d} / \mathrm{d}}$

271 females (Fig. 4c).

272 Interestingly, loss of Men1 led to decreased Cdkn1b (encoding p27) in both

273 mRNA and protein levels (Fig. 4c, f). Especially, immunohistochemical analysis

274 indicated that the expression of p27 was higher in polyploid cells (Fig. 4f).

275 Previous studies manifest that increased p27 level in liver cells causes a failure

276 to enter mitosis and thereby induces polyploidy ${ }^{31}$. Reduced polyploid decidual 
277 cell in $M e n 1^{\mathrm{d} / \mathrm{d}}$ decidual tissues might be account for the reduction of $\mathrm{p} 27$. In 278 addition, gene set enrichment analysis (GSEA) analysis showed that 279 cytokinesis associated genes (Rhoc, Rhob, Dstn $)^{32}$ were significantly enriched 280 by Men1 loss (Fig. 4g, h and Supplementary Data 5). Consistently, there were 281 more stromal cells undergoing proliferating in Men1 knockout SDZ as 282 evidenced by significant increase of mitotic marker pH3 (Fig. 4i, j). Above all, 283 Men1 loss had a strong negative impact on normal physiological changes in 284 decidualization.

Men1-deficient uteri show diminished BMP responsiveness but enhanced

\section{FGF responsiveness}

As aforementioned, uterine with Men1 deletion had an insufficient terminal differentiation of stromal cells in the SDZ. Interestingly, FGF signaling pathway that positively regulated cell proliferation was significantly enriched among the up-regulated genes in Men1/d uteri. In contrast, gene set responding to BMP which motivated differentiation of stromal cells was significantly suppressed in

Men $1^{\mathrm{d} / \mathrm{d}}$ uteri (Fig. 5a, b and Supplementary Data 5). During decidualization,

294 Fgf2 transcript was localized in the undifferentiated stromal cells underneath 295 the myometrium ${ }^{6}$. FGF2 binds and activates the tyrosine kinase receptor 296 complex FGFR1-FRS2 and recruits the downstream GRB2-SOS1 complex to 297 incite ERK1/2 signaling cascade which is a major pathway controlling cell 298 proliferation ${ }^{33}$. Fgfr1 and Frs2 but not the ligand Fgf2 were significantly 
increased by Men1 deletion (Fig. 5b, c). BMP2 is a well-known decidual marker critical for the differentiation of stromal cells during decidualization ${ }^{6,8}$. The expression of $B m p 2$ and its target $I d 1$ was substantially lower in Men $1^{1 / d}$ mice uteri on day 8 of pregnancy (Fig. 5b, d). BMPs execute their effects by inducing the phosphorylation of SMAD1/5/8 proteins. Accordingly, the protein level of $p$ SMAD1/5/8 was decreased in Men $1^{\text {d/d }}$ decidual cells (Fig. 5e). Interestingly, both the significant elevated expression of Fgfr1 and reduced expression of Bmp2 caused by Men1 deletion mainly occurred in the SDZ (Fig. 5f). We also observed an elevation of phosphorylated ERK1/2 in Men $1^{\mathrm{d} / \mathrm{d}}$ stromal cells in the SDZ (Fig. 5g). These observations were consistent with enrichment of ERK1/2 cascade and decreased cell differentiation observed in Men $1^{\mathrm{d} / \mathrm{d}}$ decidual tissues (Fig. 4b, c). Thus, spatiotemporal decidualization regulated by programmed FGF signaling and BMP signaling was disorganized in Men1 deficiency uterine. Indeed, mutually inhibitory effects between FGF and BMP signaling are common module throughout embryogenesis ${ }^{34}$. Next, we explored whether there was a cross-talk between BMP2 and FGF2-ERK1/2 signals, and what role Menin played in this communication during the development of the SDZ.

\section{Menin positively regulates the expression of Ptx3 in a H3K4me3} dependent manner

Menin is an indispensable component of MLL1/2 HMT complex that catalyzes $\mathrm{H} 3 \mathrm{~K} 4 \mathrm{me} 3$ at gene promoter, which is usually associated with 
transcriptional activation of genes ${ }^{9}$. In order to define the distribution of Menin on genome and its relevance to gene expression in decidual cells, we performed ChIP-seq for Menin and H3K4me3 in decidual tissues on day 8. Consistent with the published literature, Menin and $\mathrm{H} 3 \mathrm{~K} 4 \mathrm{me} 3$ is predominantly positioned at gene promoter (Menin peaks: $n=10,230,76.65 \%$ at promoters; H3K4me3 peaks: $n=26,002,70.62 \%$ at promoters) (Fig. 6a). Combined with RNA-seq data, we found that Menin and H3K4me3 was significantly enriched at the transcription start site (TSS) of expressed genes (RPKM>1) (Fig. $6 \mathrm{~b}$ and Supplementary Fig. 6a). H3K4me3 was specifically reduced at TSSs rather than genebodies in the absence of Menin (Fig. 6b). A direct comparison of Menin and H3K4me3 ChIP-seq peaks at gene promoters showed a strong positive correlation $\left(R^{2}=0.5888291\right)$ (Fig. 6c). The promoters of 6,800 genes bound by Menin ( $92 \%$ of all genes with promoter bound by Menin) were also H3K4me3 modified (Supplementary Fig. 6b). We therefore focused on the potential functional relationship between Menin and H3K4me3 in gene transcriptional activation during decidualization.

We speculated that Menin activated gene expression through H3K4me3 by interacting with MLL1/2 during decidualization. The Kmt2a (encoding MLL1) and $K m t 2 b$ (encoding MLL2) mRNA levels were not affected by the absence of Men1 (Supplementary Fig. 6c). We utilized the RIME (Rapid immunoprecipitation mass spectrometry of endogenous proteins) ${ }^{35}$ to identify the interactome networks of endogenous Menin protein in decidual tissues. As 
expected, subunits of MLL1/2 complex, MLL1, MLL2, WDR5, DPY30, OGT and PSIP1 were pulled down by Menin (Fig. 6d and Supplementary Data 6). Albeit total H3K4me3 protein level was not affected by Men1 ablation (Supplementary Fig. 6d), read coverage of $\mathrm{H} 3 \mathrm{~K} 4 \mathrm{me} 3$ at promoters was significantly reduced at the absence of Men1 ( $p<2.2 \mathrm{e}-16)$ (Fig. 6e). Analysis of ChIP-seq data revealed that although Menin directly binding at the promoters of Menin-MLL typical target genes (e.g. Cdkn1b, Cdkn2c, Esr1, Hoxa cluster and Meis1) in decidual tissue, none of them had H3K4me3 reduction after Men1 deletion (Fig. 6f). Correspondingly, except for the decreased expression of Cdkn1b, the mRNA levels of other Menin target genes had no significant difference in the absence of Men1 (Fig. 4c, 6f). There might be an alternative mechanism different from H3K4me3 dependent mechanism as previously reported participated in the transcriptional regulation of $C d k n 1 b$ by Menin ${ }^{13}$. According to these results, we hypothesized that Men1 regulates the transcription of a subset of decidualspecific target genes through $\mathrm{H} 3 \mathrm{~K} 4 \mathrm{me} 3$ modification.

In Men $1^{\mathrm{fff}}$ decidual cells, Menin and H3K4me3 showed prominent colocalization around the transcription start site (TSS) \pm 3 kilobases (kb) (Fig. 6b, g and Supplementary Fig. 6a, e). H3K4me3 peaks were classified into two clusters depending on the changes after Men1 deletion (Fig. $6 \mathrm{~g}$ and Supplementary Fig. 6e). We focused on cluster 1 containing loci where H3K4me3 ChIP-seq signal was strongly decreased following Men1 deletion, representing 6,469 associated genes (Fig. 6g). To identify the direct Menin- 
H3K4me3 target genes responsible for the decidualization defects observed in Men $1^{\mathrm{d} / \mathrm{d}}$ uteri, we intersected the data of RNA-seq with the Menin and H3K4me3 ChIP-seq results and found 2,995 potential Menin-H3K4me3 direct target genes. Among them, only 348 exhibited a significant decrease in mRNA levels following Men1 deletion (Fig. 6h). In these potential target genes, Ptx3 attracted our attention since it was one of the top ten down-regulated genes upon Men1 deletion (Fig. 6i). Furthermore, deletion of Ptx3 resulted in compromised decidualization ${ }^{36}$. Indeed, Men1 loss decreased Ptx3 expression in decidual tissues on day 8 of pregnancy (Fig. 7a). Following Men1 deletion, the peak of H3K4me3 was significant reduced at the Ptx3 locus and RNA-seq tracks for Ptx 3 was profoundly decreased in Men $1^{\mathrm{d} / \mathrm{d}}$ uteri (Fig. $\left.7 \mathrm{~b}\right)$. Through Menin ChIP assays using a pair of specific primers targeting the Ptx 3 promoter locus, we further confirmed that Ptx3 was a direct target gene of Menin in decidual cells (Fig. 7c). Meanwhile, H3K4me3 occupancy at the Ptx3 promoter locus was dramatically decreased in Men1-knockout stromal cells (Fig. 7d). These results suggested that Menin upregulate Ptx3 expression in a H3K4me3 dependent manner.

\section{Menin inhibits the cross-talk between FGF2-ERK1/2 and BMP2 by} regulating the transcription of $P$ tx 3

PTX3 has been shown to bind with selected FGFs, including FGF2 and FGF8b, through its $\mathrm{N}$-terminal domain, and sequester them in the extra cellular 
matrix, thus inhibiting their biological effects ${ }^{37}$. As described above, Men1 loss up-regulated FGF response. We found Ptx3 specifically expressed in the SDZ close to the thin layer of undifferentiated stromal cells where Fgf2 located, and significantly decreased following Men1 deletion (Fig. 7e). During embryogenesis, FGF2 is considered to be a paracrine factor and is essential for tissue patterning and organogenesis ${ }^{34}$. Based on these results, we 393 considered that the decrease of Ptx 3 caused by Men1 deficiency contributed to excessive ERK1/2 activation induced by paracrine FGF2 produced by the layer of undifferentiated stromal cells. To confirm this conjecture, primary mouse 396 endometrial stromal cells (mESC) isolated from day 4 uterus of 397 pseudopregnancy were cultured with or without recombinant mouse PTX3 in 398 the presence of FGF2. PTX3 treatment for $72 \mathrm{~h}$ significantly inhibited the 399 phosphorylation of ERK1/2 induced by FGF2 in mESC compared with cells 400 without PTX3 treatment (Fig. 7f). Consistent with previous studies, the inhibitory 401 effect of PTX3 on FGF2 was conserved during mouse decidualization. Thus, 402 we concluded Menin suppressed the activation of FGF2-ERK1/2 signaling 403 pathway in the SDZ by modulating Ptx3 transcription through epigenetic 404 H3K4me3 modification.

405 In the preceding results, Men1 loss decreased BMP response program (Fig. 406 5). Indeed, suppression of BMP signaling by FGF2 sustained undifferentiated 407 proliferation of human ES cells ${ }^{38}$. Next, we explored whether the reduction of 408 BMP2 was caused by abnormal highly activated FGF2-ERK1/2 signal in the 
absence of Men1. During in vitro decidualization of mESC induced by E2 and P4, the expression pattern of Menin was almost consistent with that of BMP2 in spite of the slight decrease expression of Menin after $96 \mathrm{~h}$ of decidualization (Supplementary Fig. 7a). MI-503, a Menin inhibitor, blocks the Menin/MLL interaction and trigger Menin protein degradation via ubiquitin-proteasome pathway ${ }^{39}$. MI-503 treatment for $48 \mathrm{~h}$ reduced the expression of Menin protein without affecting the mRNA level of Men1 during the decidualization of mESC (Supplementary Fig. 7b, c). The expression of Menin target gene Ptx3 was also significantly reduced upon MI-503 treatment (Fig. 7g). However, MI-503 treatment for $72 \mathrm{~h}$ did not affect the expression of BMP2 and the activity of ERK1/2 during mESC decidualization (Supplementary Fig. 7d), implying Bmp2 was not a direct target of Menin and consistent with the ChIP data showing no Menin occupying and comparable H3K4me3 modification at Bmp2 promoter upon Men1 knockout (Supplementary Fig. 7e). While in the presence of exogenous FGF2, MI-503 treatment resulted in decreased BMP2 and elevated ERK1/2 phosphorylation (Fig. 7h). Meanwhile co-treatment with MEK inhibitor PD0325901 reversed the reduction of BMP2 induced by MI-503 (Fig. 7h). These results demonstrated FGF2 acting as a paracrine factor had an inhibitory effect on BMP2 expression during decidualization. Supplementation of exogenous PTX3 also inhibited excessive activation of ERK1/2 and recovered BMP2 level (Fig. 7h). These results suggested Menin regulated the expression of BMP2 during decidualization by setting PTX3 as a trap for FGF2-ERK1/2 
pathway, thereby ensuring the success of decidualization. 


\section{Discussion}

The regulatory machinery of endometrial heterogeneity and decidua regionalization after embryo implantation disturb scientists for long time due to the scarcity of suitable mouse model. Developmentally associated transcription factors HOXA10, whose expression expanded throughout the PDZ and SDZ, have been reported playing an important role in establishing region-specific decidual tissue during decidualization ${ }^{7,40}$. While, other potential participants in decidua regionalization remained largely unknown. Here, we demonstrated that uterine Men1, which was spatiotemporally expressed during decidualization, guided the stromal cells towards the fate of terminal differentiation by directing histone modification rewiring, guaranteeing the expansion of the SDZ boundary during regionalization of decidualization.

Previous studies indicated that spatiotemporal expression pattern of Bmp2 with the progression of decidualization contributed to highly heterogeneous of decidual cells $\mathbf{s}^{1,6}$. At the initiation of decidualization, distinct accumulation of Bmp2 in the subepithelial stroma was essential for blastocyst attachment reaction at the implantation site ${ }^{2,6,8}$. With the spatiotemporal progression of decidualization, expanded Bmp2 expression in the PDZ and SDZ was critical for the terminal differentiation of stromal cells ${ }^{6,8}$. A significant decrease of Bmp2 in the SDZ on day 8 caused by Men1 deficiency disturbed the terminal differentiation of stromal cells during the expansion of SDZ without affecting the blastocyst attachment reaction and the PDZ formation. 

the expression of target genes including Hoxa genes, Cdkn1b and Cdkn2c, 456 Esr1 and $p 35$ through connecting with histone methyltransferases MLL1/2 $11-15$. 457 There was a dramatic whole genomic chromatin alteration in human 458 endometrium decidualization marked by histone modification and chromatin 459 accessibility ${ }^{41,42}$. However, the role of H3K4me3 modification in decidual 460 regionalization remained elusive. Distinctive histone methyltransferases in 461 large COMPASS-like complexes performed non-redundant histone 462 modifications in various cell types ${ }^{43}$. The SET1A/B family is responsible for 463 genome-wide bulk H3K4me2/H3K4me3 modification and the MLL3/4 complex 464 family mediates $\mathrm{H} 3 \mathrm{~K} 4 \mathrm{me} 1$ modification at enhancers and super-enhancer ${ }^{43}$. 465 MLL1/2 complex, containing unique subunit Menin, is responsible for H3K4me3 466 modification at certain genes in cell specific manner ${ }^{11,43}$. In this study, we 467 depicted the H3K4me3 profiling in regionalized decidualization during early 468 pregnancy and unraveled its regulatory apparatus by Menin.

Among the direct targets marked by Menin-H3K4me3 during stroma 470 decidualization, Ptx3 involved in decidualization regulation possesses specific 471 expression pattern in the $\mathrm{SDZ}^{36}$, but its physiological significance in stromal cell 472 differentiation remains intangible. Several pieces of evidences showed that 473 PTX3 acted as a natural FGF2 trap through its N-terminal domain to sequester 474 FGF2-ERK1/2 signaling from promoting cell proliferation ${ }^{37}$. Interestingly, our 475 investigation demonstrated that Men1-deficient uteri showed augmented 
FGF2-FGFR1-ERK1/2 signaling activity in the SDZ at the absence of PTX3.

This abnormality subsequently reduced $B m p 2$ and blocked cell differentiation in the SDZ. Consistent with previous studies, the inhibitory effect of PTX3 on FGF2 was conserved during mouse decidualization. Indeed, the homeostasis between BMP and FGF has been described as "constituting a common module" throughout embryogenesis ${ }^{34,44}$. FGF signaling inhibited the expression of BMPs in dorsal mesoderm, thus limiting their expression to ventral mesoderm for proper dorsoventral axis specification ${ }^{45}$. Inhibition of BMP activity by the FGF signal promoted posterior neural development ${ }^{46}$. Furthermore, suppression of BMP signaling by FGF2 sustained undifferentiated proliferation of human ES cells $^{38}$. Consistently, we evidenced that the discouraged cross-talk between BMP2 and FGF2 coordinated by Menin regulated PTX3 facilitated the maturation of decidua, which was further supported by the mutually exclusive expression of Bmp2 and Fgf2 in the SDZ and undifferentiated stromal cells, respectively. Together, we provided insightful evidence that the uncomfortable cross-talk between stromal cells in different regions through paracrine manner was curbed under the precise orchestrating of PTX3.

Moreover, Men1 deficiency disrupted the polyploidization in the SDZ with reduced large mono or bi-nucleated polyploid cells as evidenced by H3K27me3. In female somatic cells, the punctate immunostaining of H3K27me3 stand for inactivated $\mathrm{X}$ chromosome ${ }^{24}$. Somatic cells with two or more punctate H3K27me3 in nuclei was considered as polyploid cells. Currently, flow 
498

499

500

501

502

503

504

505

506

507

508

cytometry was the major way to evaluate the polyploid stromal cells. Here, we established a new visible method to estimate the polyploidization which will greatly advance the mechanism study for polyploidy.

Previously studies suggested that endoreduplication and the absence of cytokinesis were the primary reasons for polyploidization of stromal cells which were mediated by various cyclin associated proteins ${ }^{3,5,26}$. Here, we found that cytokinesis program was significantly enriched in Men1 ${ }^{\mathrm{d} / \mathrm{d}}$ decidual cells. We also provided previously unappreciated mechanism for this black box. Cdkn1b (encoding p27), a recognized Menin-MLL1/2 target gene ${ }^{13}$, was decreased in Men $1^{\mathrm{d} / \mathrm{d}}$ uteri. Furthermore, multiple observations proved that female mice lacking functional p27 were infertile ${ }^{47-49}$. Furthermore, based on the observation that p27 induced polyploidy of liver cells without cytokinesis ${ }^{31,50}$, we speculated p27 also participated in regulating decidual cell polyploidization. Though the mRNA of Cdkn1b was reduced, the $\mathrm{H} 3 \mathrm{~K} 4 \mathrm{me} 3$ modification at the promoter of

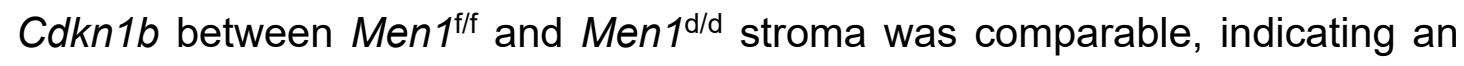
alternative regulation of Menin on Cdkn1b which deserved further investigation. Collectively, our results provided a new perspective that the patterning of decidual cells into disparate fates through the concerted activity of BMP and FGF signaling pathways underpinned the progression of decidualization. Results reported here revealed that the blunt induction of BMP2 caused by unrestrained FGF2-ERK1/2 signaling activity deranged the development of SDZ due to disorganized genomic H3K4me3 distribution in the absence of 
520 Men1. The previously unappreciated PTX3, an extra-cellular trap for FGF2, was

521 identified as a critical Menin-H3K4me3 regulated downstream gene in decidual

522 regionalization and pregnancy maintenance by curbing the cross-talk between

523 FGF2-ERK1/2 and BMP2. Our finding will remarkably advance our knowledge 524 on current model of decidualization and inspire future studies for human fertility 525 improvement. 


\section{Methods and Materials}

\section{Animals}

528 Men1-floxed mouse line $\left(M^{2} 1^{f / f}\right)$ was constructed as previously described ${ }^{10}$.

529 Uterine-specific knockout mice $\left(M e n 1^{\mathrm{d} / \mathrm{d}}\right)$ were generated by mating Men $1^{\mathrm{f} / \mathrm{f}}$ 530 females with $\mathrm{Pgr}^{\mathrm{cre} /+}$ males ${ }^{16}$. Mice were housed in the animal care facility of 531 Xiamen University according to the guidelines for the care and use of laboratory 532 animals. All experimental procedures were approved by the Animal Welfare 533 Committee of Research Organization (X200811), Xiamen University.

\section{Analysis of pregnancy events}

536 Pregnancy events were analyzed as described previously ${ }^{17}$. Briefly, 2-month537 old female mice were mated with fertile wild type males to induce pregnancy 538 (vaginal plug = day 1 of pregnancy). Plug-positive females were kept separately 539 for pregnant experiments. Pregnancy rate and litter size were monitored for the 540 whole pregnancy process. For day 5 and day 6 pregnant mice, implantation 541 sites were visualized by an intravenous injection of $100 \mu \mathrm{L}$ of $1 \%$ Chicago blue 542 in saline. The number and average weight of implantation sites demarcated by 543 distinct blue bands was recorded. Uterine horns were flushed to check for the 544 presence of embryos if no blue band was observed. Mouse blood samples were 545 collected on day 6 and serum E2 as well as P4 levels were measured by 546 radioimmunoassay. At least three mice were used for every individual 547 experiment in each mouse model. 


\section{Artificial decidualization model}

Pseudopregnant mice were obtained by mating females with vasectomized males of the same strain. To induce artificial decidualization, one uterine horn of pseudopregnant mice was infused with sesame oil $(25 \mu \mathrm{l})$ on day 4 ; the noninfused contralateral horn taken as a control. The weight of infused and noninfused uterine horns was recorded 4 days after the oil infusion and the fold increase in uterine weights was served as an index of decidualization ${ }^{23}$.

\section{In situ hybridization}

In situ hybridization with isotopes or digoxygenin (DIG) was modified according to the previously described method ${ }^{23}$. Frozen sections $(10 \mu \mathrm{m})$ were mounted onto poly-L-lysine coated slides and stored at $-80^{\circ} \mathrm{C}$ until used. After removal from $-80^{\circ} \mathrm{C}$, the slides were placed on a slide warmer $\left(37^{\circ} \mathrm{C}\right)$ for 3 minutes and then fixed in $4 \%$ paraformaldehyde in PBS for 15 minutes at $4^{\circ} \mathrm{C}$. Following prehybridization, uterine sections were hybridized to specific cRNA probes overnight at $65^{\circ} \mathrm{C}$. After hybridization, the slides were incubated with RNase A (10 mg/ml) at $37^{\circ} \mathrm{C}$ for 30 minutes. RNase A-resistant hybrids were detected by autoradiography using liquid emulsion or AP labeled anti-DIG antibody. Mousespecific cRNA probes labeled with isotope or digoxin for Men1, Bmp2, Dan, Igfbp5, Bmp7, Wnt4, Prl8a2, Hoxa10, Ptn, Sfrp4, Ptx3 and Fgfr1 were used for hybridization. 
570

571 The tissue specimens were fixed overnight in 10\% neutral buffered formalin and

572 then dehydrated in increasing concentrations of ethyl alcohol, followed by

573 clearing of alcohol by xylene. Uterine slices were deparaffinized and incubated

574 in citrate buffer for antigen retrieval by hyperbaric heating and then incubated 575

576 COX2 (Santa Cruz, 1:200), Dtprp (homemade, 1:200), Ki-67 (Abcam,1:200),

577 PL1 (Santa Cruz, 1:200), 3ß-HSD (Santa Cruz, 1:200), p450scc (Santa Cruz, 578 1:200), PR (CST, 1:200), HAND2 (Santa Cruz, 1:200), p27(abcam,1:100), pH3 579 (CST, 1:200), ERK1/2 (CST, 1:200) and p-ERK1/2 (CST, 1:200). A Histostain580 SP Kit (Zhongshan Golden Bridge Biotechnology) was applied to visualize the 581 antigen. Immunofluorescence staining for OCT4 (CST, 1:200), $\beta$-Catenin 582 (Epitomics, 1:200), H3K27me3 (CST, 1:200), BrdU (Abcam, 1:500) and PCNA 583 (Epitomics, 1:200) was performed in paraffin-fixed sections and secondary 584 antibodies conjugated with Cy3 dyes were used. The images were captured by 585 Leica DM2500 light microscope. Antibodies with detailed information are listed 586 in Supplementary Table 1.

587

\section{Western blot}

589 Decidual cells were isolated as described previously ${ }^{17}$. The proteins were 590 separated by using 10\% SDS-PAGE and transferred to polyvinylidene difluoride membranes. And then the membranes with proteins were blocked with $5 \%$ skim 
592 593

594 595 596 597 598 599 600 601 602 603 604 605 606 607 608 609 610

612 Flow cytometric analysis was performed as previously described ${ }^{23}$. Day 8 613 decidual cells were digested and harvested. The cell pellet was suspended in

milk in TBST for $1 \mathrm{~h}$ at room temperature (RT) and incubated overnight at $4^{\circ} \mathrm{C}$ with primary antibody for Menin (Bethyl, 1:2000), $\beta$-Actin (Bioworld, 1:3000), Dtprp (homemade, 1:2000), p27 (Abcam, 1:500), ERK1/2 (CST, 1:1000), pERK1/2 (CST, 1:1000), BMP2 (Abcam, 1:500), SMAD1/5/8 (CST, 1:1000), pSMAD1/5/8 (CST, 1:1000), H3K4me3 (Abcam, 1:2000) and H3 (Abmart, 1:2000). After incubation with primary antibody, membranes incubated with specific secondary antibodies (Zhongshan Golden Bridge Biotechnology, 1:5000) for $2 \mathrm{~h}$ at RT. Bands were visualized using Supersignal West Pico (Thermo Scientific) according to the manufacturer's instructions. Antibodies with detailed information are listed in Supplementary Table 1.

\section{Quantitative real-time PCR}

Quantitative real-time PCR was performed as described previously ${ }^{17}$. Total RNA was extracted from uterine tissues or cells using TRIzol reagent (Invitrogen) following the manufacturer's protocol. About $1 \mu \mathrm{g}$ RNA was used to synthesize cDNA. Expression levels of the genes were validated by quantitative real-time PCR analysis with SYBR Green (TAKARA). All assays were performed at least three times. All PCR primers are listed in Supplementary Table 2.

\section{Flow cytometry} decidual cells were digested and harvested. The cell pellet was suspended in 
$6140.25 \mathrm{ml}$ PBS after centrifugation; $1 \mathrm{ml}$ of cold $80 \%$ ethanol was added dropwise 615 under constant and gentle vortexing. Samples were incubated for 30 min on ice 616 and subsequently overnight at $-20^{\circ} \mathrm{C}$ before subjected to staining. Cell 617 sediments were suspended in staining solution (PBS containing $5 \mathrm{mg} / \mathrm{ml}$ 618 Propidium lodide and $2 \mathrm{mg} / \mathrm{ml}$ DNase-free RNase A) the next day. Samples 619 were incubated for $30 \mathrm{~min}$ at $37^{\circ} \mathrm{C}$ in the dark. They were then returned to RT 620 and subjected to flow cytometry. The experiments were repeated three times.

\section{RNA-seq}

623 Total RNA was extracted from day 8 decidua (dissect out the embryo and 624 muscle layer) of $M e n 1^{\mathrm{f} / \mathrm{f}}$ and littermates Men $1^{\mathrm{d} / \mathrm{d}}$ using TRIzol reagent 625 (Invitrogen) according to the manufacturer's protocol. Purified RNA was 626 prepared and subjected to RNA sequencing using BGISEQ-500 platform (China, 627 BGI). RNA-seq raw data were initially filtered to obtain clean data after quality 628 control by Trimgalore. High-quality clean data were aligned to the mouse 629 reference genome $(\mathrm{mm} 10)$ using HISAT2.

\section{$631 \quad$ RNA-Seq data analysis}

632 Differential expression genes were normalized to fragments per kilobase of 633 exon model per million mapped reads (RPKM) using EdgeR package in $\mathrm{R}$ with 634 the criteria of fold change significantly greater than 1.5 and $p<0.05$. Gene 635 ontology (GO) enrichment analysis of differential expression genes (DEGs) was 
637 Integrated Discovery, https://david.ncifcrf.gov). GO terms with corrected $p$ $638<0.05$ were considered significantly enriched. Gene Set Enrichment Analysis 639 (GSEA) was performed to determine whether a defined set of genes shows 640 statistically significant differences between $M e n 1^{\mathrm{f} / \mathrm{f}}$ and littermates $M e n 1^{\mathrm{d} / \mathrm{d}}$ 641 decidual tissues.

\section{ChIP-Seq}

644 Chromatin immunoprecipitation (ChIP) was modified and performed according 645 to the previous described standard protocol ${ }^{51}$. Decidual tissue wetted with PBS 646 quickly cut into small pieces with an iris scissor. Snipped tissue was fixed with $6471 \%$ formaldehyde (CST) for 10 mins at RT (for H3K4me3 ChIP), or fixed with 648 disuccinimidyl glutarate (DSG, Santa Cruz, $2 \mathrm{mM}$ ) for 30 mins at RT and then 649 double fixed with $1 \%$ formaldehyde for another 10 mins at RT (for Menin ChIP). 650 Fixation was stopped by glycine $(0.125 \mathrm{M})$. Tissue homogenate obtained by 651 using Dounce Tissue Grinder was filtered through a $200 \mu \mathrm{m}$ cell strainer to 652 remove connective tissue. Fixed cells were lysed by Lysis Buffer 1 (50 mM 653 HEPES pH 7.5, 1 mM EDTA, 140 mM NaCl, 0.5\% NP-40, 10\% glycerol, 0.25\% 654 Triton X-100), Lysis Buffer 2 (10 mM Tris-HCl pH8.0, 1 mM EDTA, 0.5 mM EGTA, $655200 \mathrm{mM} \mathrm{NaCl}$ ) and Lysis Buffer 3 (10 mM Tris-HCl pH8.0, 1 mM EDTA, 0.5 mM 656 EGTA, $100 \mathrm{mM} \mathrm{NaCl}, 0.1 \%$ Sodium Deoxycholate, 0.1\% N-lauroylsarcosine). 657 All lysis buffers should be supplemented with protease inhibitors cocktail 
658 (Roche) before use. Chromatin DNA was sheared to average 300-500 bp by 659 using a BioRuptor sonicator (Diagenode). Solubilized chromatin was 660 centrifuged to remove debris and incubated overnight at $4^{\circ} \mathrm{C}$ with antibody 661 Menin (Bethyl, $10 \mu \mathrm{g}$ ) and H3K4me3 (Abcam, $1 \mu \mathrm{g}$ ) bound to $20 \mu \mathrm{l}$ protein A 662 magnetic beads (Invitrogen). After washing and elution, the protein-DNA 663 complex was reversed by heating at $65^{\circ} \mathrm{C}$ overnight. Immunoprecipitated DNA 664 was purified by using QIAquick spin columns (Qiagen). Immunoprecipitated and 665 input DNA were quantified using Qubit 4.0 fluorometer. ChIP-seq libraries were 666 prepared by using the KAPA DNA Hyper Prep Kit (KK8502) following the 667 manufacturer's instruction and sequenced with an Illumina Nova PE150. For 668 ChIP-qPCR, chromatin was sheared by sonication until the average length of 669 500-1000 bp. Specific primers were used to detect immunoprecipitated 670 chromatin fragments, as well as input chromatin.

671

672 RIME

673 Rapid immunoprecipitation mass spectrometry of endogenous proteins (RIME) 674 for analysis of complexes interact with Menin was performed as previously 675 described ${ }^{35}$. Snipped decidual tissue was fixed with $2 \mathrm{mM}$ DSG for 30 mins at 676 RT followed by incubation in $1 \%$ formaldehyde for 10 min. Crosslinking was 677 quenched by glycine $(0.125 \mathrm{M})$. Tissue homogenate obtained by using Dounce 678 Tissue Grinder was filtered through a $200 \mu \mathrm{m}$ cell strainer to remove connective 679 tissue. Fixed cells were lysed by Lysis Buffer 1 (50 mM HEPES pH 7.5, 1 mM 
680

681

682

683

684

685

686

EDTA, $140 \mathrm{mM} \mathrm{NaCl}, 0.5 \%$ NP-40, 10\% glycerol, 0.25\% Triton X-100), Lysis Buffer 2 (10 mM Tris-HCl pH8.0, 1 mM EDTA, 0.5 mM EGTA, 200 mM NaCl) and Lysis Buffer 3 (10 mM Tris-HCl pH8.0, 1 mM EDTA, 0.5 mM EGTA, 100 $\mathrm{mM} \mathrm{NaCl}, 0.1 \%$ Sodium Deoxycholate, $0.1 \% \mathrm{~N}$-lauroylsarcosine). All lysis buffers should be supplemented with protease inhibitors cocktail (Roche) before use. Chromatin was sheared by sonication to produce DNA fragments of 500-1000 bp. $20 \mu \mathrm{l}$ Protein A (Invitrogen) and $5 \mu \mathrm{g}$ Menin antibody (Bethyl) or rabbit IgG antibody (CST) were used for each sample. The bead-bound antibody and chromatin were incubated overnight at $4^{\circ} \mathrm{C}$. The next day the beads were washed 10 times with $1 \mathrm{ml}$ RIPA buffer and twice with $500 \mu \mathrm{l} 100 \mathrm{mM}$ AMBIC (Ammonium Bicarbonate). A volume of $10 \mu$ trypsin solution (Pierce, 15 $\mathrm{ng} / \mathrm{\mu l}$ ) in $100 \mathrm{mM}$ AMBIC was added to the beads followed by overnight incubation at $37{ }^{\circ} \mathrm{C}$. The beads adsorbed protein-antibody complex directly placed into formic acid to give a final concentration of $5 \%$. MS experiments were performed on Thermo Scientific ${ }^{\mathrm{TM}}$ Orbitrap Fusion ${ }^{\mathrm{TM}}$ Lumos $^{\mathrm{TM}}$ Tribrid $^{\mathrm{TM}}$.

\section{Primary uterine stromal cell culture}

Primary uterine stromal cells were isolated and cultured as previously described $^{23}$. Three to four pseudopregnant day 4 mouse uterine horns were cut into small pieces $(2-3 \mathrm{~mm})$. Tissue pieces were first digested in $3 \mathrm{ml}$ fresh medium (HBSS antibiotic; Gibco) containing $6 \mathrm{mg} / \mathrm{ml}$ dispase (Gibco) and $25 \mathrm{mg} / \mathrm{ml}$ pancreatin (Sigma), and then incubated in fresh medium containing 
702

703

704

705

706

707

708

709

710

711

712

713

714

715

716

717

718 719 result.

720

721

722

723

$0.5 \mathrm{mg} / \mathrm{ml}$ collagenase (Sigma) at $37^{\circ} \mathrm{C}$ for $30 \mathrm{~min}$. The digested cells were passed through a $70 \mu \mathrm{m}$ filter to obtain the stromal cells. Cells were plated at $60 \mathrm{~mm}$ dishes or 6-wells plates, containing phenol red-free Dulbecco modified Eagle medium (DMEM) and Ham F12 nutrient mixture (1:1) (Gibco) with $10 \%$ charcoal-stripped fetal bovine serum (CS-FBS) and antibiotic. Two hours later, the medium was replaced with fresh medium (DMEM/F12, 1:1) with $10 \%$ CSFBS. The next morning, the medium was replaced with DMEM/F12 containing 1\% C-FBS, E2 (Sigma, $10 \mathrm{nM}), \mathrm{P} 4$ (Sigma, $1 \mu \mathrm{M})$ and antibiotic to induce decidualization. The media was changed every $48 \mathrm{~h}$. For the treatment of primary uterine stromal cells, MI-503 ( $2 \mu \mathrm{M}$; MedChemExpress), recombinant murine FGF2 (PeproTech, 20 ng/ml), recombinant mouse PTX3 (R\&D systems, $100 \mathrm{ng} / \mathrm{ml}$ ) and MEK inhibitor PD0325901 (Selleck, 5 M) were used.

\section{Statistical analysis}

All data are presented as mean \pm SEM. Each experiment included at least three independent samples. Comparison between two groups were made by twotailed unpaired Student's t-test. $p<0.05$ was considered to indicate a significant

\section{Data availability}

The datasets generated and analyzed in the study are available in the NCBI Gene Expression Omnibus (GEO). RNA-seq and ChIP-Seq data sets 
generated in this study have been deposited at the Gene Expression Omnibus database under accession number GSE182525 (token: uvqrgucctdqrxyp) and GSE182539 (token: ufuxseswvbkzpep), respectively. All custom scripts can be accessed upon request to the corresponding author.

\section{Acknowledgements}

We are grateful to Prof. Francesco DeMayo (National Institute of Environmental Health Sciences) for providing us with the $\mathrm{Pgr}^{\mathrm{Cre} /+}$ mice. Thanks for $\mathrm{Bo} \mathrm{He}$ and Yufei Jiang in lab for animal model establishment. This work was supported by National Key R\&D program of China (2018YFC1004400 to S.K., 2017YFC1001402 to H.W., 2018YFC1004100 to W.D.), National Natural Science Foundation of China (31970797 to Z.L, 81830045 and 82030040 to H.W., 81971388 to S.K, 81701483 and 81971419 to W.D.), Fundamental Research Funds for the Central Universities (20720190073 to W.D.).

\section{Author contributions}

M.L., W.D., L.T., M.L., and C.G. performed experiments and prepared figures. M.L., W.D., J.L., S.K., H.W. and Z.L. designed experiments. C.Z. provided the Men1 loxp mouse model. M.L., W.D. and S.K. analyzed data. M.L., H.B., W.D., S.K., H.W. and Z.L. wrote the manuscript.

\section{Competing interests}

The authors declare that they have no competing interests. 


\section{References}

7481 Wang, H. \& Dey, S. K. Roadmap to embryo implantation: clues from mouse models. Nat Rev Genet. 7, 185-199 (2006).

2 Yuan, J. et al. Primary decidual zone formation requires Scribble for pregnancy success in mice. Nat Commun. 10, 5425 (2019).

7523 Das, S. K. Cell cycle regulatory control for uterine stromal cell 753 decidualization in implantation. Reproduction. 137, 889-899 (2009).

4 Daikoku, T. et al. Uterine Msx-1 and Wnt4 signaling becomes aberrant 755 in mice with the loss of leukemia inhibitory factor or Hoxa-10: evidence for a novel cytokine-homeobox-Wnt signaling in implantation. Mol Endocrinol. 18, 1238-1250 (2004). successful pregnancy. Nat Med. 18, 1754-1767 (2012). Cha, J., Sun, X. \& Dey, S. K. Mechanisms of implantation: strategies for Paria, B. C. et al. Cellular and molecular responses of the uterus to embryo implantation can be elicited by locally applied growth factors. Proc Natl Acad Sci U S A. 98, 1047-1052 (2001).

Daikoku, T. et al. Proteomic analysis identifies immunophilin FK506 binding protein 4 (FKBP52) as a downstream target of Hoxa10 in the periimplantation mouse uterus. Mol Endocrinol. 19, 683-697 (2005).

8 Lee, K. Y. et al. Bmp2 is critical for the murine uterine decidual response. Mol Cell Biol. 27, 5468-5478 (2007). menin: emerging opportunities for restoration of transcriptional 
regulation in MEN1. Endocr Relat Cancer. 24, T135-T145 (2017).

Yokoyama, A. et al. The menin tumor suppressor protein is an essential oncogenic cofactor for MLL-associated leukemogenesis. Cell. 123, 207218 (2005).

13 Milne, T. A. et al. Menin and MLL cooperatively regulate expression of cyclin-dependent kinase inhibitors. Proc Natl Acad Sci U S A. 102, 749-

14 Dreijerink, K. M. A. et al. Enhancer-Mediated Oncogenic Function of the Menin Tumor Suppressor in Breast Cancer. Cell Rep. 18, 2359-2372 (2017).

15 Zhuang, K. et al. Neuron-Specific Menin Deletion Leads to Synaptic Dysfunction and Cognitive Impairment by Modulating p35 Expression. Cell Rep. 24, 701-712 (2018). express the progesterone receptor. Genesis. 41, 58-66 (2005).

Zhang, S. et al. Uterine Rbpj is required for embryonic-uterine orientation and decidual remodeling via Notch pathway-independent and dependent mechanisms. Cell Res. 24, 925-942 (2014).

E. Insulin-like growth factor binding protein gene expression in the pregnant rat uterus and placenta. Dev Biol. 184, 278295 (1997).

21 Monsivais, D. et al. BMP7 Induces Uterine Receptivity and Blastocyst Attachment. Endocrinology. 158, 979-992 (2017).

22 Li, Y., Dewar, A., Kim, Y. S., Dey, S. K. \& Sun, X. Pregnancy success in mice requires appropriate cannabinoid receptor signaling for primary 
decidua formation. Elife. 9 (2020).

80723 Wang, Q. et al. Wnt6 is essential for stromal cell proliferation during decidualization in mice. Biol Reprod. 88, 5 (2013).

24 Tjalsma, S. J.

D. et al. H4K20me1 and H3K27me3 are concurrently loaded onto the inactive $\mathrm{X}$ chromosome but dispensable for inducing gene silencing. EMBO Rep. 22, e51989 (2021).

25 Gaynor, L. M. \& Colucci, F. Uterine Natural Killer Cells: Functional

$27 \mathrm{Yu}, \mathrm{H}$. F. et al. Ptn functions downstream of C/EBP $\beta$ to mediate the

Distinctions and Influence on Pregnancy in Humans and Mice. Front Immunol. 8, 467 (2017).

29 Fagiani, E. \& Christofori, G. Angiopoietins in angiogenesis. Cancer Lett. 328, 18-26 (2013).

30 Cui, Y. et al. Role of corin in trophoblast invasion and uterine spiral artery remodelling in pregnancy. Nature. 484, 246-250 (2012).

32 Piekny, A., Werner, M. \& Glotzer, M. Cytokinesis: welcome to the Rho zone. Trends Cell Biol. 15, 651-658 (2005).

33 Ornitz, D. M. \& Itoh, N. The Fibroblast Growth Factor signaling pathway. Wiley Interdiscip Rev Dev Biol. 4, 215-266 (2015).

83534 Dorey, K. \& Amaya, E. FGF signalling: diverse roles during early 
vertebrate embryogenesis. Development. 137, 3731-3742 (2010).

83735 Papachristou, E. K. et al. A quantitative mass spectrometry-based approach to monitor the dynamics of endogenous chromatin-associated protein complexes. Nat Commun. 9, 2311 (2018).

84036 Tranguch, S., Chakrabarty, A., Guo, Y., Wang, H. \& Dey, S. K. Maternal pentraxin 3 deficiency compromises implantation in mice. Biol Reprod.

37 Ronca, R. et al. Long-Pentraxin 3 Derivative as a Small-Molecule FGF

$38 \mathrm{Xu}, \mathrm{R}$. H. et al. Basic FGF and suppression of BMP signaling sustain 846 undifferentiated proliferation of human ES cells. Nat Methods. 2, 185190 (2005).

41 Vrljicak, P. et al. Analysis of chromatin accessibility in decidualizing human endometrial stromal cells. Faseb j. 32, 2467-2477 (2018).

42 Katoh, N. et al. Reciprocal changes of H3K27ac and H3K27me3 at the promoter regions of the critical genes for endometrial decidualization. Epigenomics. 10, 1243-1257 (2018).

43 Schuettengruber, B., Bourbon, H. M., Di Croce, L. \& Cavalli, G. Genome 860

44 Schliermann, A. \& Nickel, J. Unraveling the Connection between Fibroblast Growth Factor and Bone Morphogenetic Protein Signaling. Int J Mol Sci. 19 (2018).

45 Fürthauer, M., Van Celst, J., Thisse, C. \& Thisse, B. Fgf signalling 
controls the dorsoventral patterning of the zebrafish embryo. Development. 131, 2853-2864 (2004).

86846 Koshida, S. et al. Inhibition of BMP activity by the FGF signal promotes 869 posterior neural development in zebrafish. Dev Biol. 244, 9-20 (2002).

$87047 \quad$ Nakayama, K. et al. Mice lacking p27(Kip1) display increased body size, 871 multiple organ hyperplasia, retinal dysplasia, and pituitary tumors. Cell. 872 85, 707-720 (1996).

87348 Kiyokawa, H. et al. Enhanced growth of mice lacking the cyclin874 dependent kinase inhibitor function of p27(Kip1). Cell. 85, 721-732 875 (1996).

87649 Fero, M. L. et al. A syndrome of multiorgan hyperplasia with features of 877 gigantism, tumorigenesis, and female sterility in p27(Kip1)-deficient mice. $878 \quad$ Cell. 85, 733-744 (1996).

$87950 \quad$ Nakayama, K. et al. Skp2-mediated degradation of p27 regulates 880 progression into mitosis. Dev Cell. 6, 661-672 (2004).

$88151 \quad$ Sabari, B. R. et al. Coactivator condensation at super-enhancers links 882 phase separation and gene control. Science (New York, N.Y.). 361 883 (2018). 
a

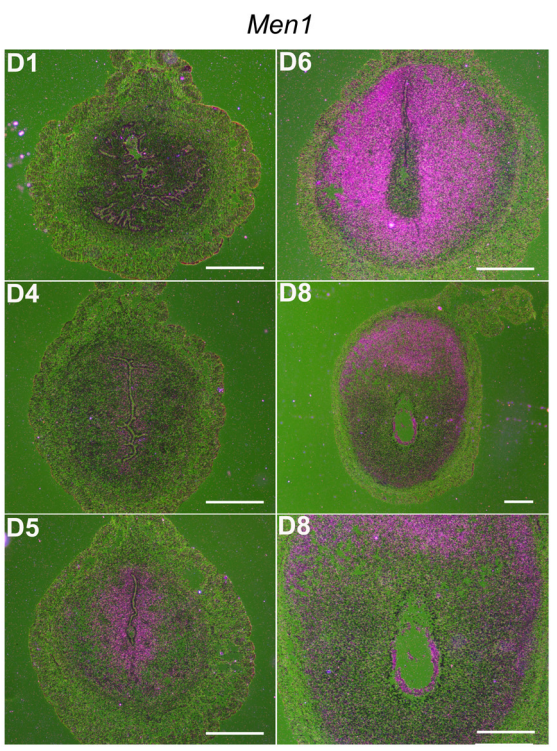

d

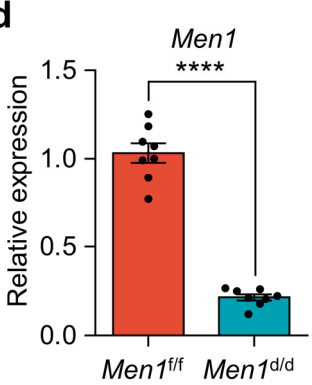

e

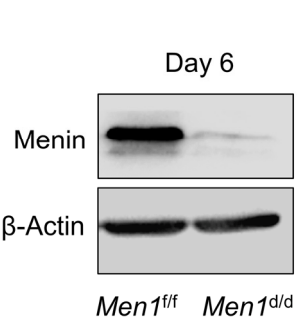

b

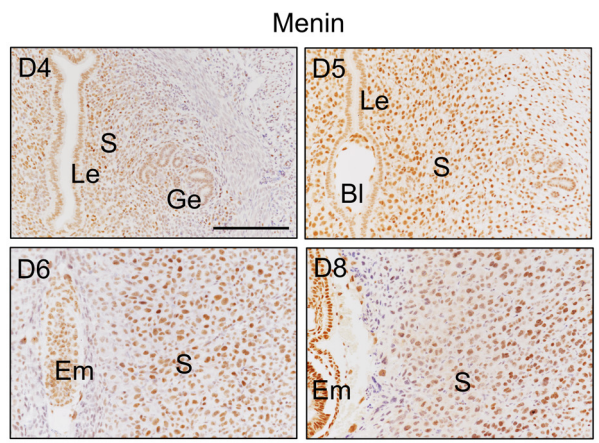

C

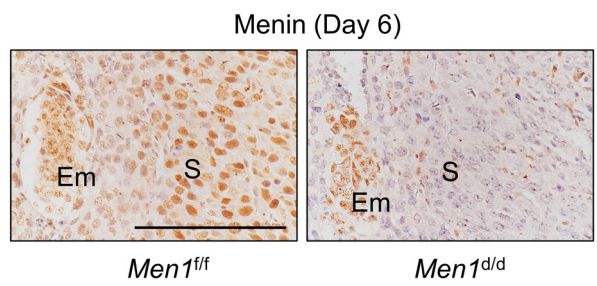

f

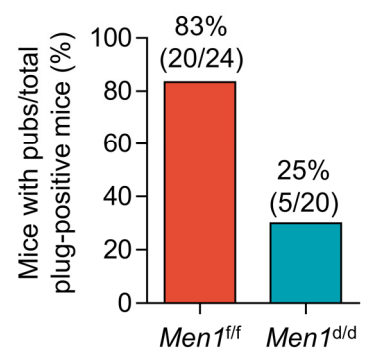

g

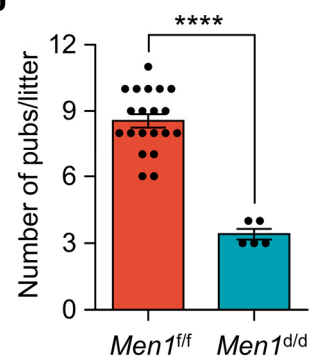

Fig. 1 Uterine-specific deletion of Men1 leads to female subfertility. (a) In situ hybridization of Men1 in WT uteri on days 1, 4, 5, 6 and 8 of pregnancy. Scale bars: $500 \mu \mathrm{m}$. (b) Immunohistochemical analysis of Menin in day 4 uteri and day 5, 6, 8 implantation sites. Le, luminal epithelium; Ge, glandular epithelium; S, stroma; BI, blastocyst; Em, embryo. Scale bar: $200 \mu \mathrm{m}$. (c)

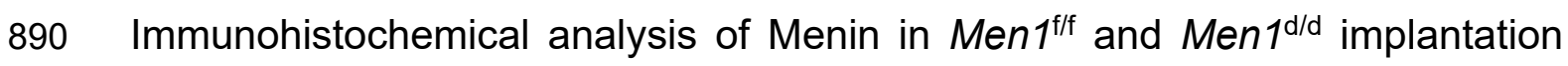
891 sites on day 6. S, stroma; Em, embryo. Scale bar: $200 \mu \mathrm{m}$. (d) Quantitative real-

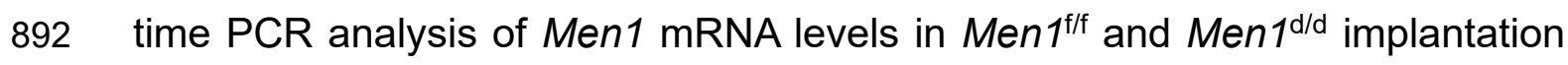
893 sites on day 6. The values are normalized to Gapdh and indicated as the mean $894 \pm$ SEM. Two-tailed unpaired Student's t test ${ }^{* * *} p<0.0001$. (e) Immunoblotting 
895 analysis of Menin protein in Men1/f/f and Men $1^{\mathrm{d} / \mathrm{d}}$ implantation sites on day $6 . \beta$ 896 Actin were used as loading controls. (f) Pregnancy rates in Men $1^{1 / f}$ and Men $1^{\mathrm{d} / \mathrm{d}}$ 897 female mice. The number within brackets indicates females with pups over total

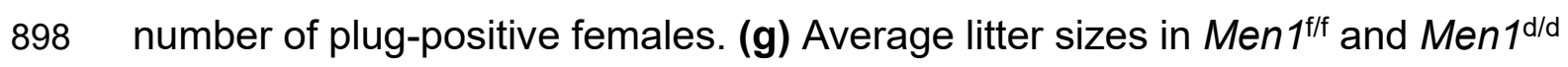
899 mice. Data represent the mean \pm SEM. Two-tailed unpaired Student's $t$ test 900 ${ }^{* * * *} p<0.0001$. 
a

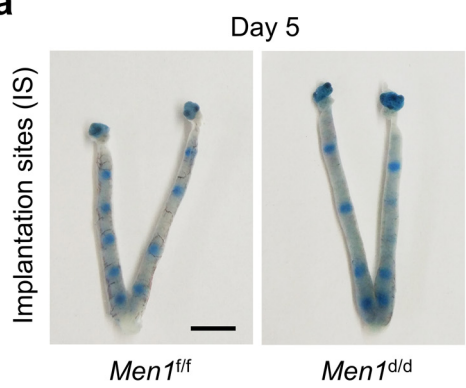

d

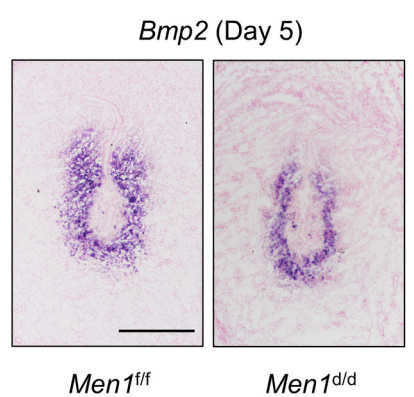

g

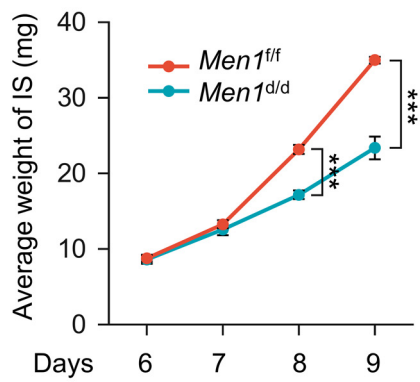

j

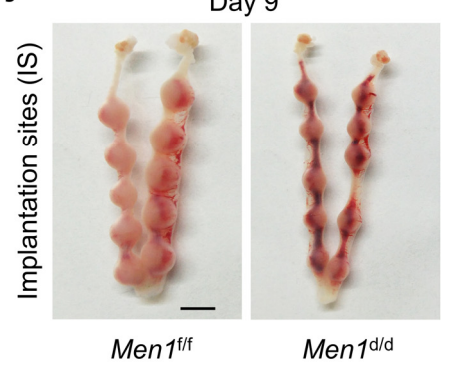

b

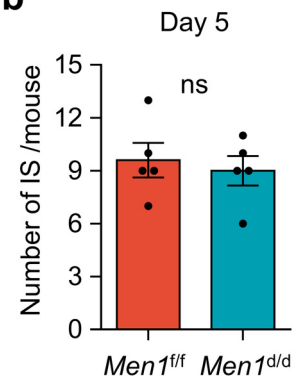

C

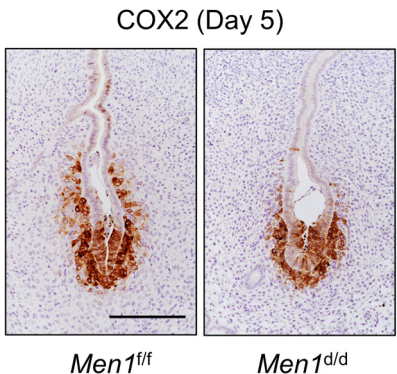

f

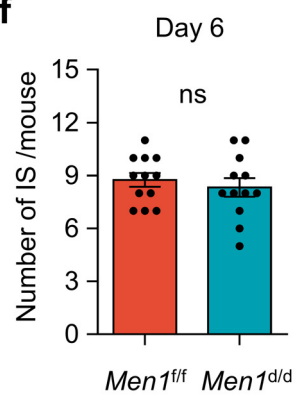

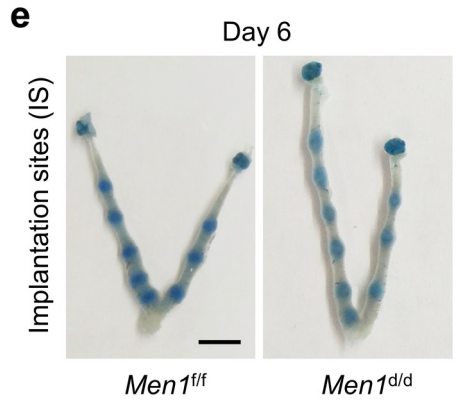

i h

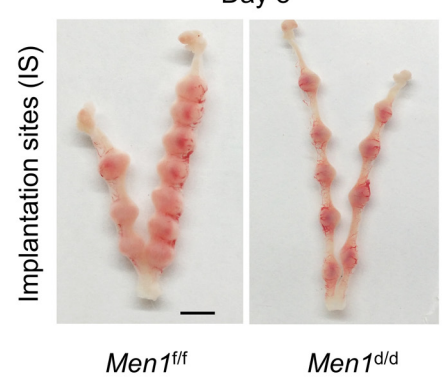

k

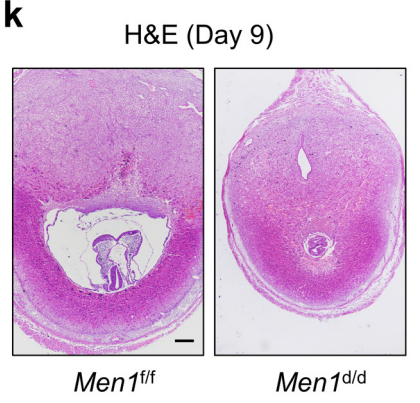
H\&E (Day 8)

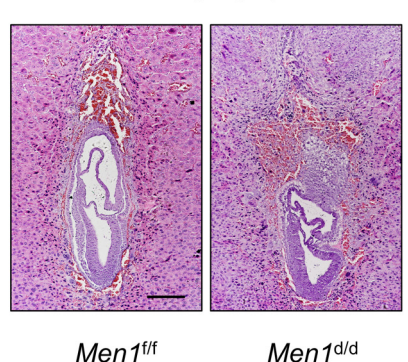

\section{I}

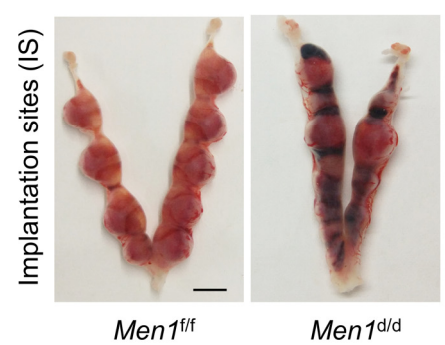

Fig. 2 Mice with uterine Men1 deletion show defective embryo

903 development at post-implantation stage. (a) Implantation sites marked by

904 Chicago blue dye solution in $M e n 1^{\text {f/f }}$ and $M e n 1^{d / d}$ mice on day 5. Scale bar: 5 $\mathrm{mm}$. (b) The average number of implantation sites in $M e n 1^{\mathrm{fff}}$ and $M e n 1^{\mathrm{d} / \mathrm{d}}$ mice 
on day 5. Data represent the mean \pm SEM. Two-tailed unpaired Student's $t$ test. ns, not significant. (c) Immunohistochemical analysis of embryo attachment reaction marker COX2 in Men $1^{\mathrm{flf}}$ and Men $1^{\mathrm{d} / \mathrm{d}}$ implantation sites on day 5. Scale

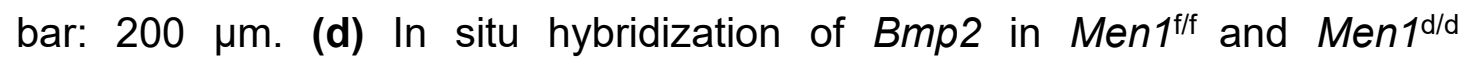
implantation sites on day 5. Scale bar: $200 \mu \mathrm{m}$. (e) Implantation sites marked by Chicago blue dye solution in Men $1^{\mathrm{fff}}$ and $M e n 1^{\mathrm{d} / \mathrm{d}}$ mice on day 6 . Scale bar: $5 \mathrm{~mm}$. (f) The average number of implantation sites in Men $1^{1 / f}$ and Men $1^{\mathrm{d} / \mathrm{d}}$ mice on day 6 . Data represent the mean \pm SEM. Two-tailed unpaired Student's $t$ test. ns, not significant. (g) The average weight of the implantation sites in Men $1^{\mathrm{f} / \mathrm{f}}$ and Men $1^{\mathrm{d} / \mathrm{d}}$ mice on days $6,7,8$ and 9 of pregnancy. Data represent the mean \pm SEM. Two-tailed unpaired Student's $t$ test ${ }^{* * *} p<0.001$. (h) Representative images of day 8 pregnant uteri in Men $1^{\mathrm{flf}}$ and Men $1^{\mathrm{d} / \mathrm{d}}$ mice. Scale bar: $5 \mathrm{~mm}$. (i) Histology of embryo development in Men $1^{1 / f}$ and Men $1^{\mathrm{d} / \mathrm{d}}$ implantation sites on day 8 of pregnancy. Scale bar: $200 \mu \mathrm{m}$. (j) Representative images of day 9 pregnant uteri in $M e n 1^{\mathrm{fff}}$ and Men $1^{\mathrm{d} / \mathrm{d}}$ mice. Scale bar: $5 \mathrm{~mm}$. (k) Histology of implantation sites in Men $1^{\mathrm{fff}}$ and Men $1^{\mathrm{d} / \mathrm{d}}$ mice on day 9 of pregnancy. Scale bar: $200 \mu \mathrm{m}$. (I) Representative images of day 12 pregnant uteri in Men $1^{1 / f}$ and Men $1^{\mathrm{d} / \mathrm{d}}$ mice. Scale bar: $5 \mathrm{~mm}$. 
a

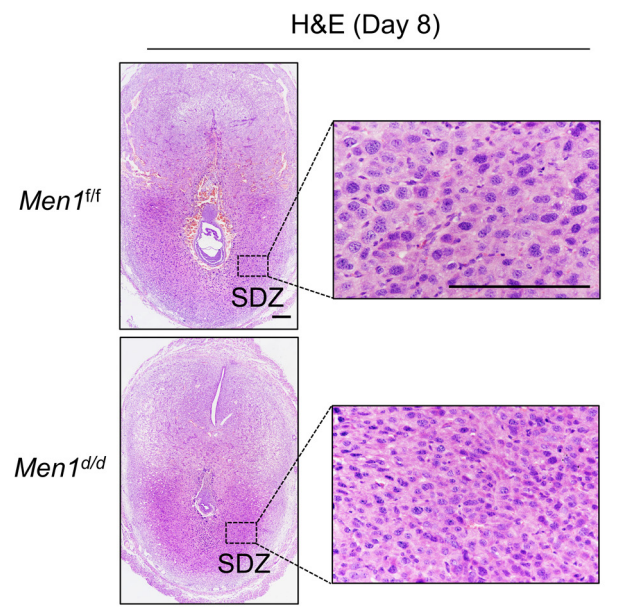

C

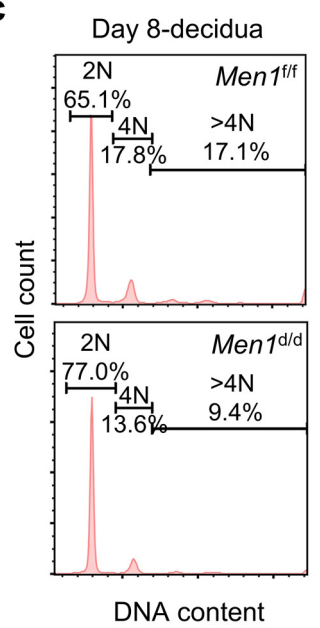

d

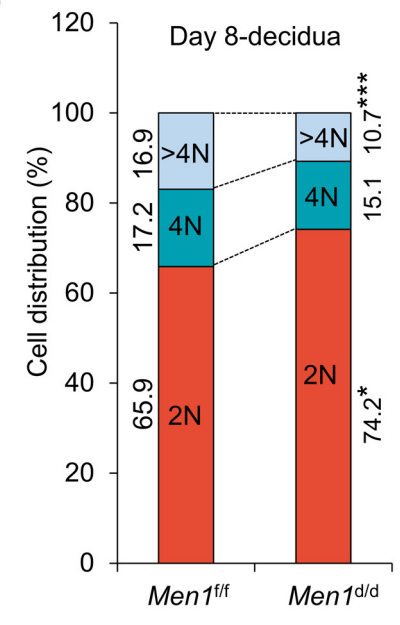

b
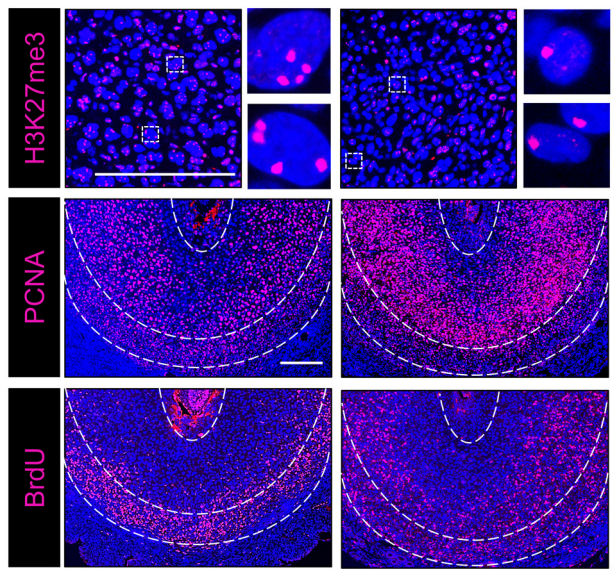

$M e n 1^{\text {t/f }}$

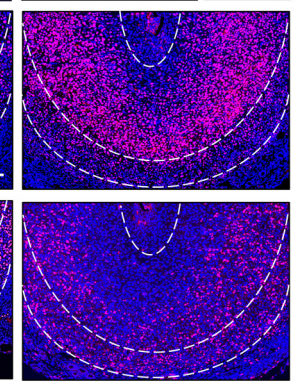

Men $1 \mathrm{~d} / \mathrm{d}$

e

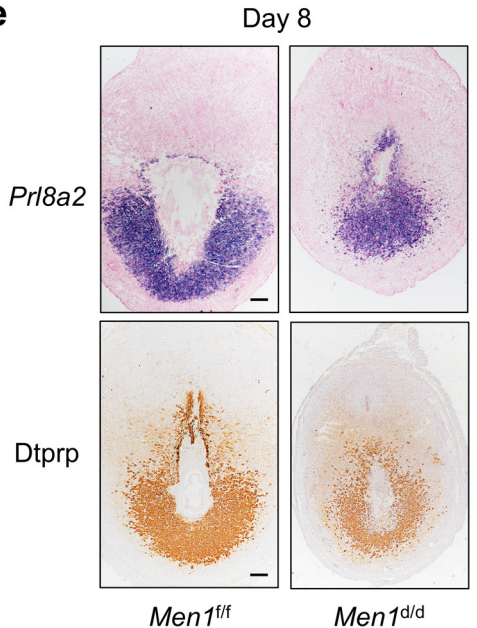

f

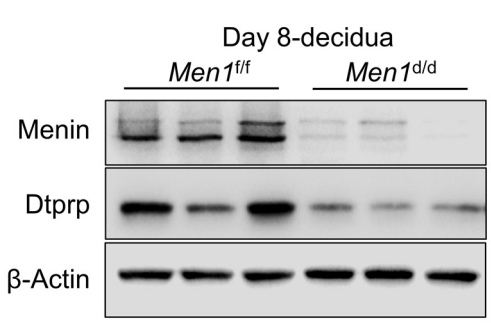

g

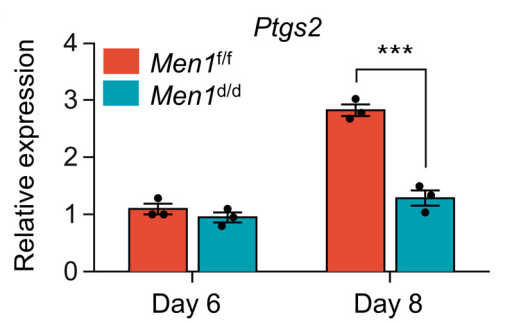

h

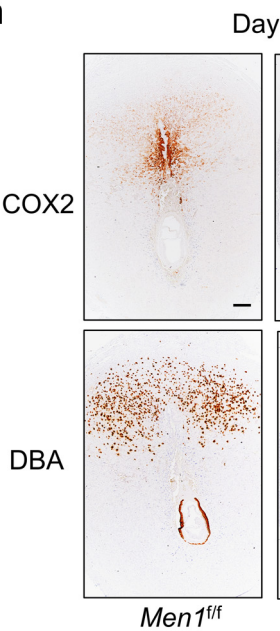

Day 8

i

PL1 (Day 8)
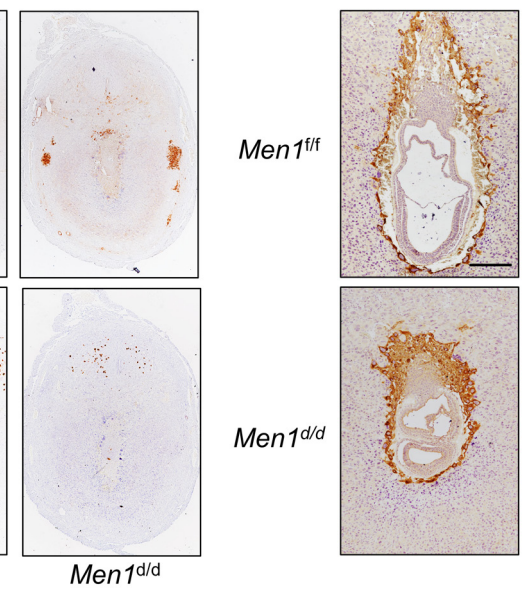

Fig. 3 Uterine Men1 deletion compromises the terminal differentiation of stromal cells with less polyploid decidual cells in the SDZ. (a) Histology of

927 day 8 implantation sites and polyploid stromal cells in $M e n 1^{\mathrm{fff}}$ and $M e n 1^{\mathrm{d} / \mathrm{d}}$ mice. 
928

929

930

931

932

933

934

935

936

937

938 Immunoblotting analysis of Dtprp in Men $1^{\mathrm{f} / \mathrm{f}}$ and $M e n 1^{\mathrm{d} / \mathrm{d}}$ implantation sites on 939

940

941

942

943

944 Scale bar: $200 \mu \mathrm{m}$. (i) Immunohistochemical analysis of PL1 in Men1/f and

$945 M e n 1^{\mathrm{d} / \mathrm{d}}$ implantation sites on day 8 . Scale bar: $200 \mu \mathrm{m}$. 


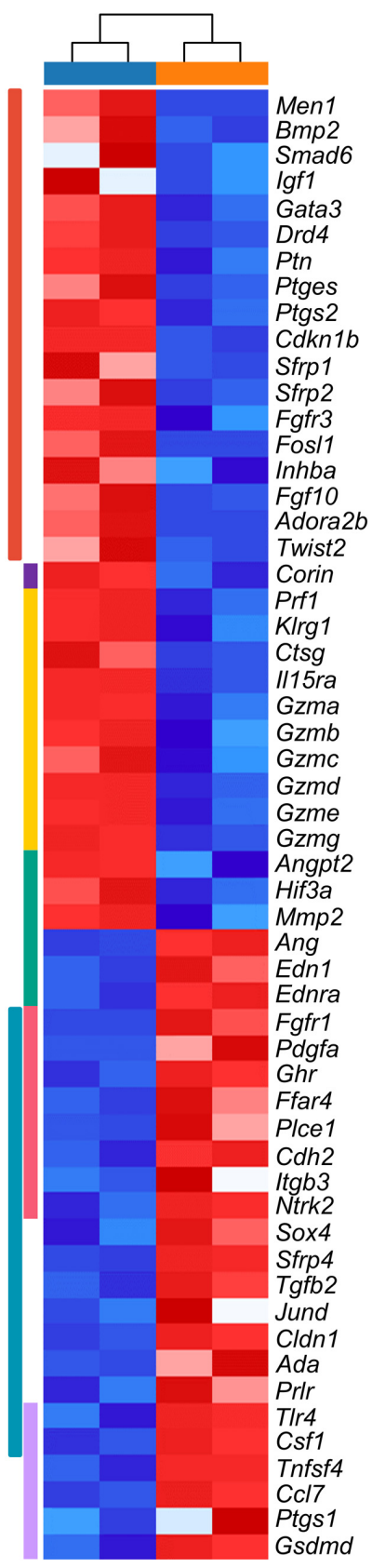

h

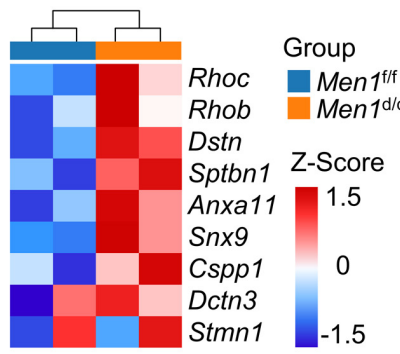

Gzme

Gzmg

Hif3a

Mmp2

Ednra

Ffr1

Ghr

far4

dh2

frp4

gfb2

Ada

Tlr4

Tnfsf4

Ptgs1

Gsdmd f
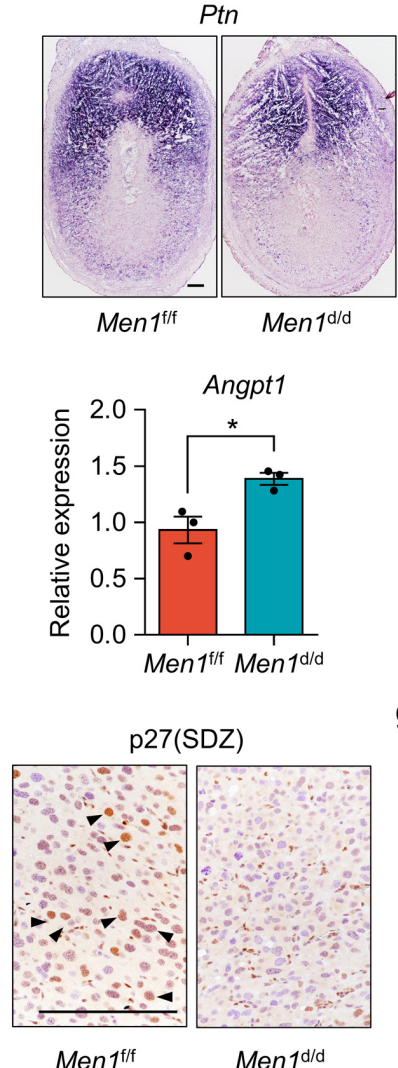

i

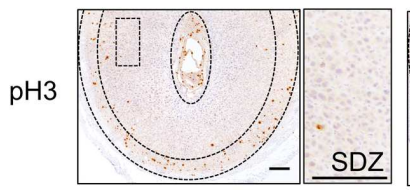

Ment/f/f g
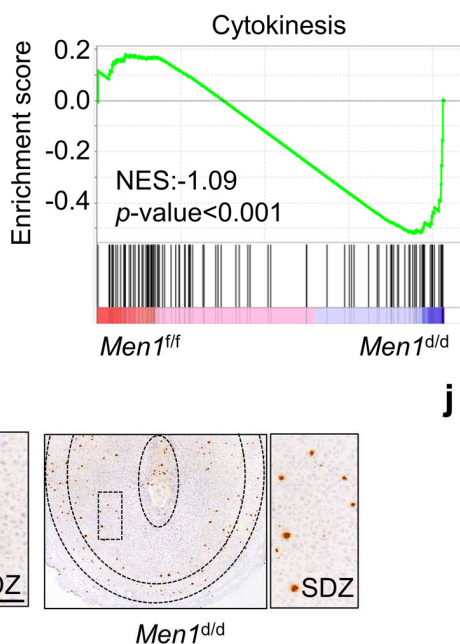

49 j

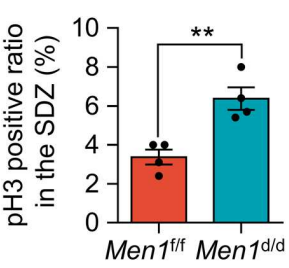

a

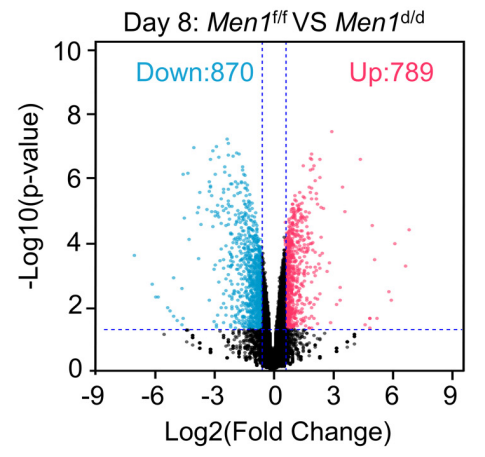

b

\begin{tabular}{l|cc|}
\hline \multicolumn{1}{|c|}{ GO category_Down } & $\mathrm{n}$ & $\log p$ \\
\hline Negative regulation of cell proliferation & 33 & -4.63 \\
Fatty acid metabolic process & 17 & -3.60 \\
Female pregnancy & 10 & -2.48 \\
Multicellular organism development & 57 & -2.47 \\
Negative regulation of angiogenesis & 9 & -2.26 \\
\hline GO category_Up & $\mathrm{n}$ & Logp \\
\hline Innate immune response & 28 & -3.55 \\
Positive regulation of apoptotic process & 23 & -2.84 \\
Positive regulation of ERK1/2 cascade & 14 & -2.07 \\
Inflammatory response & 21 & -2.06 \\
Cellular response to TNF & 10 & -2.02
\end{tabular}

C

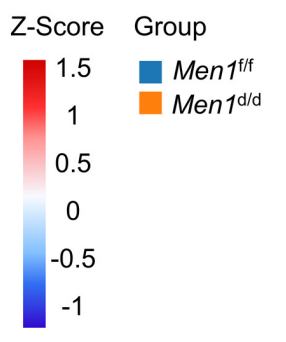

Biological function

Negative regulation of cell proliferation

Positive regulation of cell proliferation

Physiological process

uNK maturation

Spiral artery remodeling

Angiogenesis

Inflammatory response
Activation of MAPK
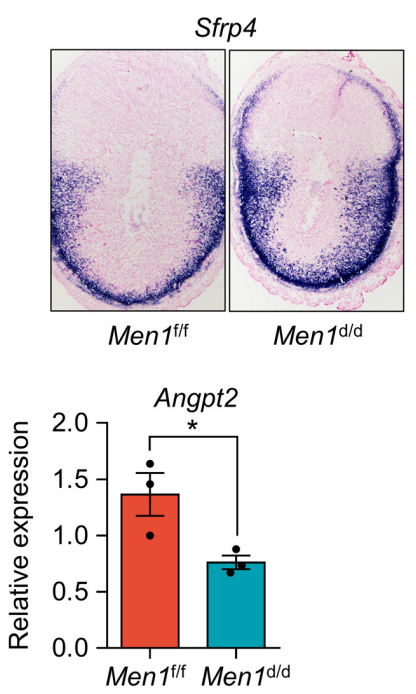

d

e

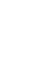

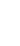


Fig. 4 Procedures for decidualization deregulated by uterine Men1 loss.

(a) Volcano plot of differentially expressed genes in Men $1^{\text {f/f }}$ and Men $1^{\mathrm{d} / \mathrm{d}}$ decidual tissues on day 8 as determined by RNA-seq. Blue and red dots represent genes that are differentially expressed $(p<0.05)$ between $M e n 1^{f / f}$ and Men $1^{\mathrm{d} / \mathrm{d}}$ decidual tissues. Genes not significantly differentially expressed are shown in black. (b) Gene Ontology $(p<0.05)$ functional analysis for differentially expressed genes determined by DAVID. n, number of genes. (c) Heatmap of physiological function associated genes differentially regulated between Men $1^{1 / f}$ and Men $1^{\mathrm{d} / \mathrm{d}}$ mice uteri on day 8. RPKM of each gene from different samples was normalized to Z-score. (d) In situ hybridization of Ptn and Sfrp4 in Men1/ff and Men $1^{\mathrm{d} / \mathrm{d}}$ implantation sites on day 8. Scale bar: $200 \mu \mathrm{m}$. (e) Quantitative real-time PCR analysis of Angpt1 and Angpt2 mRNA levels in Men1/f/f and Men $1^{\mathrm{d} / \mathrm{d}}$ implantation sites on day 8 . The values are normalized to Gapdh and indicated as the mean \pm SEM. Two-tailed unpaired Student's $t$ test ${ }^{*} p<0.05$. (f) Immunohistochemical analysis of p27 in the SDZ of Men $1^{1 / f}$ and Men1 $1^{\mathrm{d} / \mathrm{d}}$ implantation sites on day 8 . Scale bar: $200 \mu m$. (g) GSEA plot showing the enrichment of cytokinesis related genes $(n=115)$ in Men $1^{\mathrm{d} / \mathrm{d}}$ uteri compared with Men $1^{\text {fff }}$ uteri on day 8. NES, normalized enrichment score. (h) Heatmap of cytokinesis associated genes differentially expressed between $M e n 1^{\mathrm{flf}}$ and Men $1^{\mathrm{d} / \mathrm{d}}$ mice uteri on day 8 . RPKM of each gene from different samples was normalized to Z-score. (i) Immunohistochemical analysis of $\mathrm{pH} 3$ in $M e n 1^{\mathrm{fff}}$ and Men $1^{\mathrm{d} / \mathrm{d}}$ implantation sites on day 8 . Scale bars: $200 \mu \mathrm{m}$. (j) Quantitative 
969 analyses of $\mathrm{pH} 3$ positively stained cells in the SDZ on day 8. Data represent 970 the mean \pm SEM. Two-tailed unpaired Student's $t$ test ${ }^{* *} p<0.01$. 
a

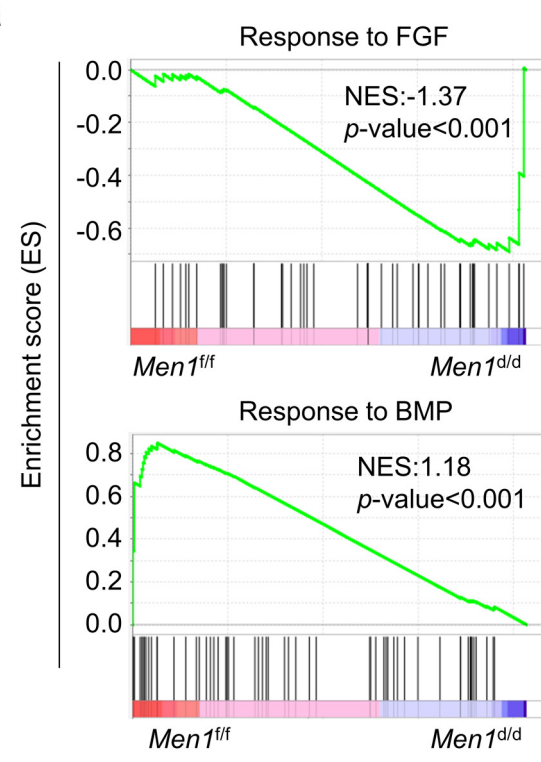

C

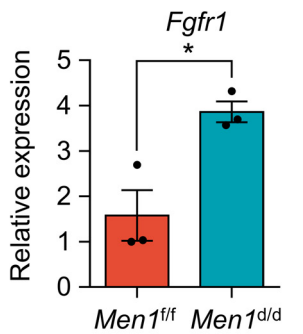

d
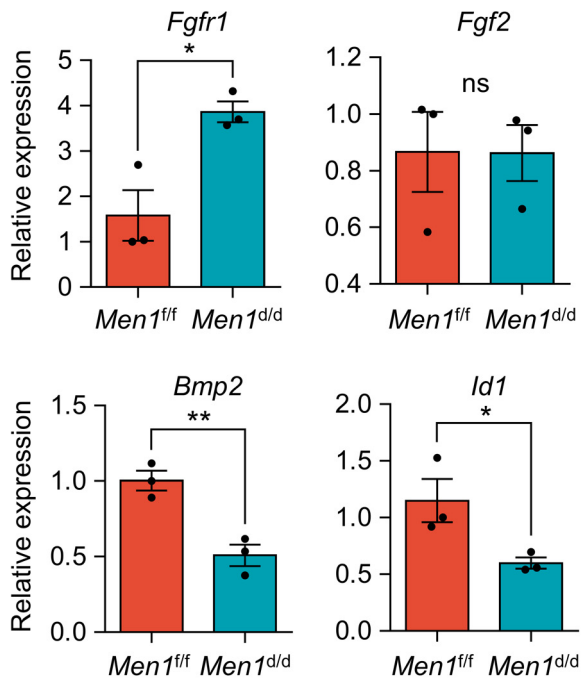

f

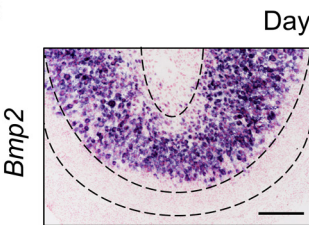

Day 8-AM
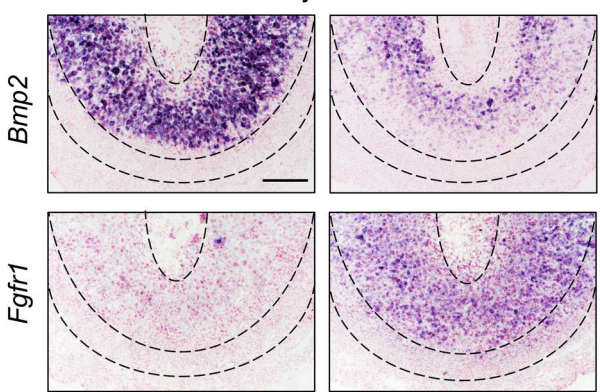

Men $1^{\text {fl/ }}$

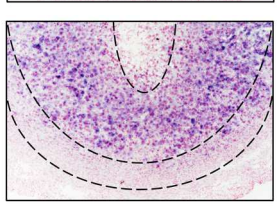

Men $1^{\mathrm{d} / \mathrm{d}}$ b

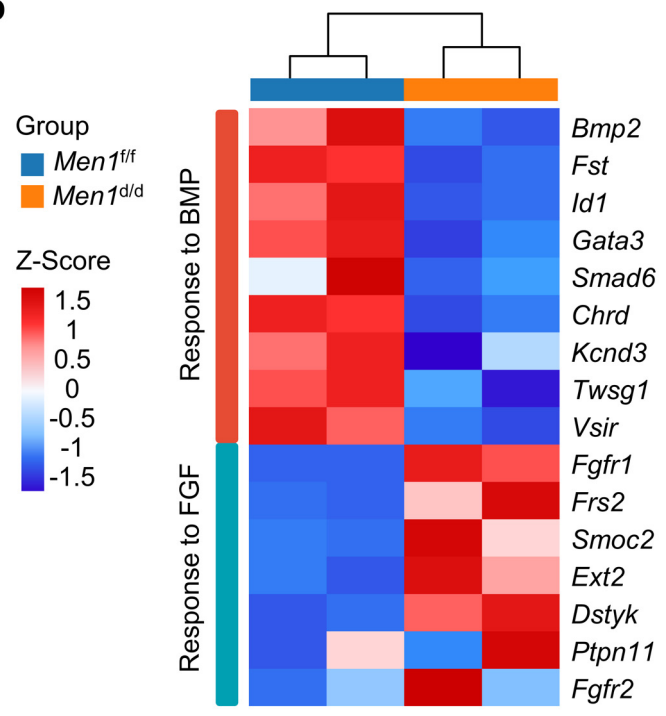

e

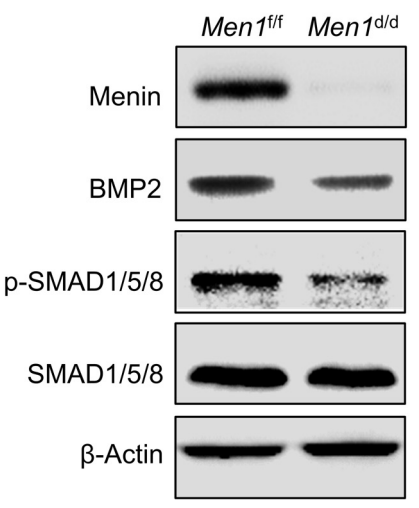

972 Fig. 5 Decidual cells in Men1-deficient uteri show diminished BMP

973 responsiveness and enhanced Fgf2 responsiveness. (a) GSEA plot

974 evaluating the changes in the indicated gene signatures of response to FGF 
$975(n=46)$ and response to BMP $(n=57)$ in $M e n 1^{\text {fff }}$ uteri compared with Men $1^{\mathrm{d} / \mathrm{d}}$ uteri.

976 NES, normalized enrichment score. (b) Heatmap of differentially expressed

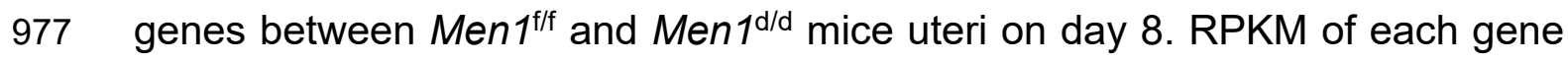
978 from different samples was normalized to Z-score. (c, d) Quantitative real-time

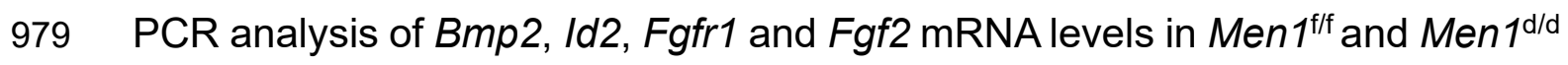
980 uteri on day 8 . The values are normalized to Gapdh and indicated as the mean $981 \pm$ SEM. Two-tailed unpaired Student's $t$ test ${ }^{*} p<0.05,{ }^{* *} p<0.01$. ns, not 982 significant. (e) Immunoblotting analysis of BMP2 and phosphorylated 983 SMAD1/5/8 in Men $1^{1 / f}$ and Men $1^{\mathrm{d} / \mathrm{d}}$ uteri. Total SMAD1/5/8 and $\beta$-Actin were 984 used as loading controls. (f) In situ hybridization of Bmp2 and Fgfr1 in Men1/f/f 985 and Men1/d/d uteri on day 8. AM, antimesometrial pole. Scale bar: $200 \mu \mathrm{m}$. (g) 986 Immunohistochemical staining of phosphorylated ERK1/2 and total ERK1/2 in $987 M e n 1^{\text {f/f }}$ and Men1/d/d uteri on day 8. Scale bar: $200 \mu \mathrm{m}$. 
a

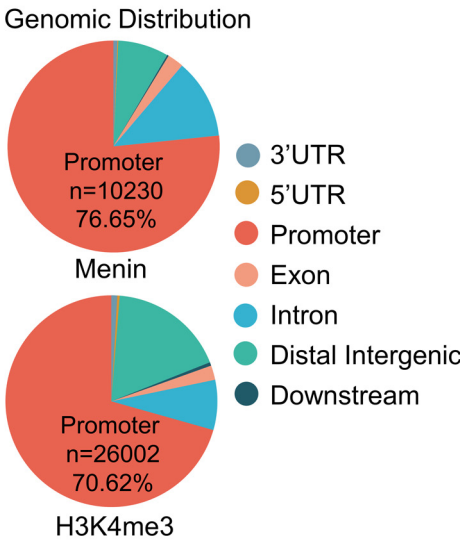

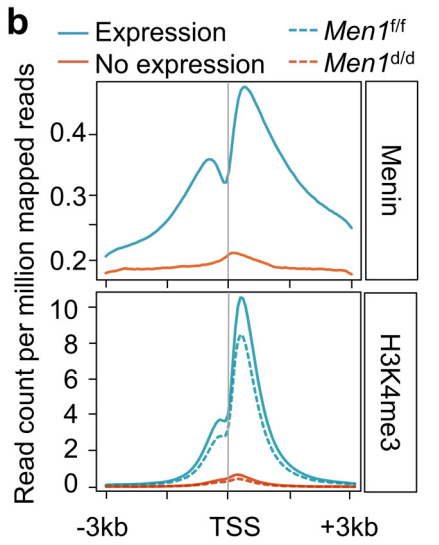

g
C

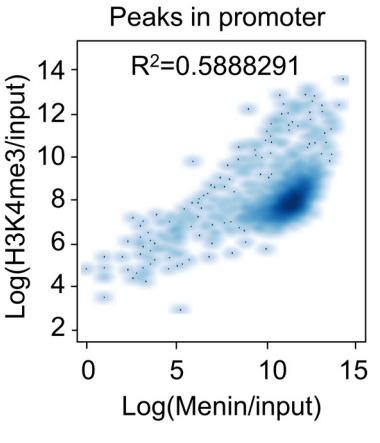

d

\begin{tabular}{|c|c|c|}
\hline \multirow{2}{*}{ Protein } & \multicolumn{2}{|c|}{ Unique Peptides } \\
\cline { 2 - 3 } & $\begin{array}{c}\text { Menin } \\
\text {-RIME }\end{array}$ & $\begin{array}{c}\text { IgG } \\
\text {-RIME }\end{array}$ \\
\hline $\begin{array}{c}\text { Menin } \\
\text { (bait) }\end{array}$ & 1 & 0 \\
\hline MLL1 & 1 & 0 \\
\hline MLL2 & 1 & 0 \\
\hline WDR5 & 1 & 0 \\
\hline DPY30 & 1 & 0 \\
\hline OGT & 2 & 0 \\
\hline PSIP1 & 3 & 0 \\
\hline
\end{tabular}

e

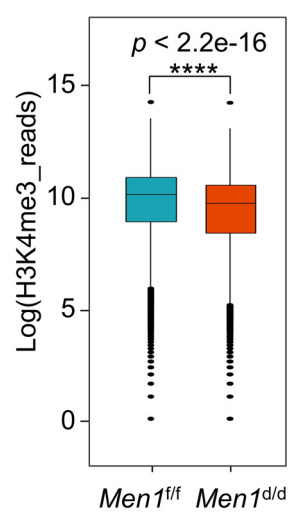

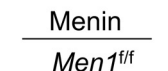

Ment ${ }^{\mathrm{flf}}$

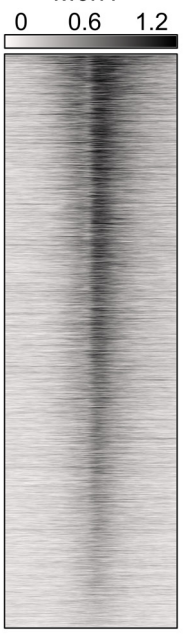

TSS

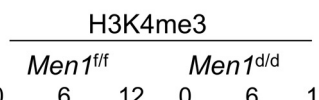

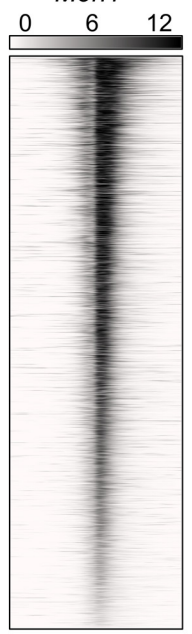

TSS

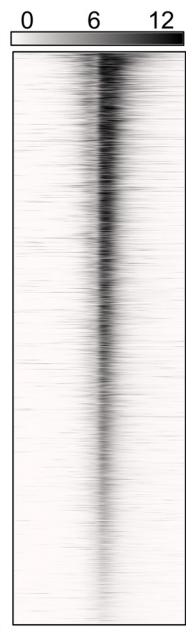

TSS
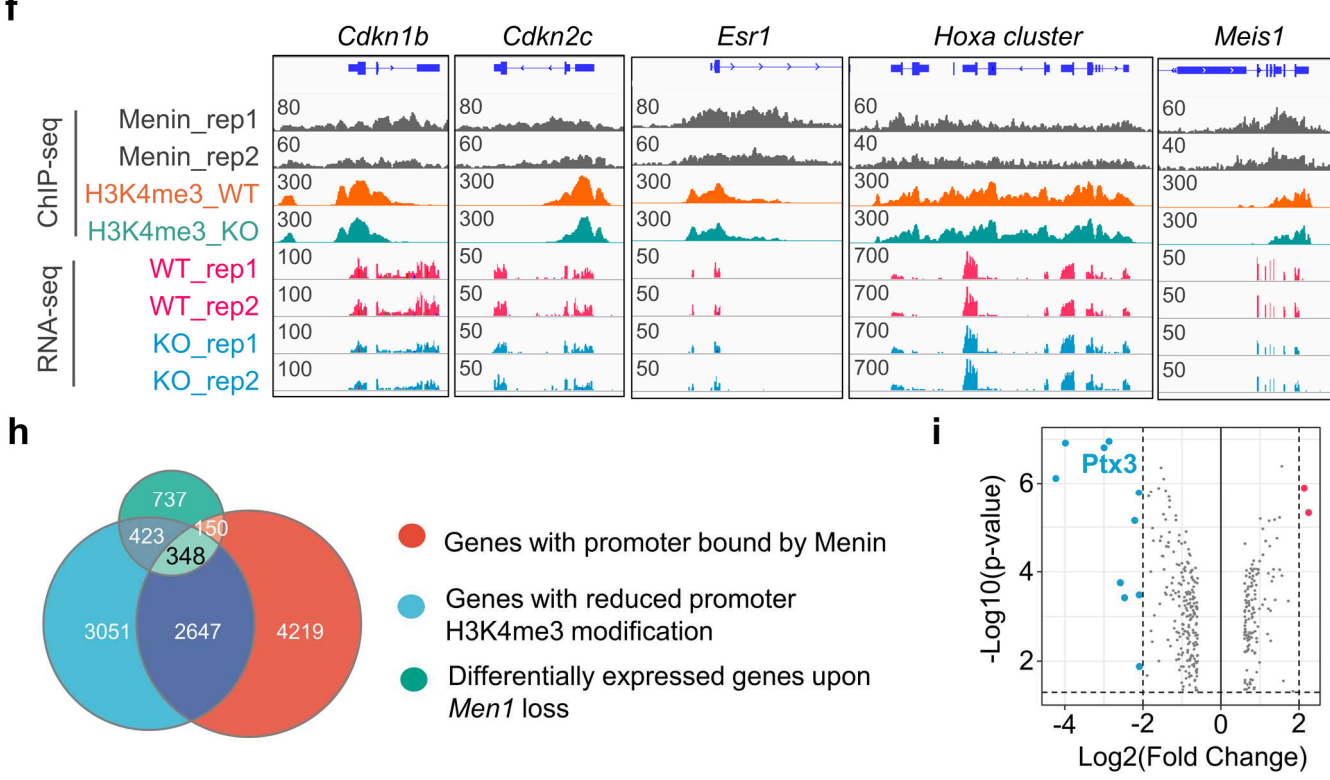

989 Fig. 6 Menin directly regulated the transcription of a small number of 
993 Correlation between Menin and H3K4me3 ChIP-seq signal in gene promoters.

$994 R^{2}=0.5888291$. (d) Proteomic analyses of endogenous Menin-binding partners.

995 (e) Change of $\mathrm{H} 3 \mathrm{~K} 4 \mathrm{me} 3$ reads number of in gene promoters between Men $1^{\mathrm{f} / \mathrm{f}}$ 996 and Men1 $1^{\mathrm{d} / \mathrm{d}}$ decidual tissues on day 8. $p<2.2 \mathrm{e}-16$. (f) Genome browser view of 997 normalized ChIP-seq signals of Menin and H3K4me3 and RNA-seq tracks of 998 known target genes in $M e n 1^{\mathrm{f} / \mathrm{f}}$ and Men1 ${ }^{\mathrm{d} / \mathrm{d}}$ decidual tissues on day $8 .(\mathbf{g})$ 999 Coverage profiles for Menin and H3K4me3. Heatmaps are centered at TSS. 10006,469 genes show significantly decreased H3K4me3 following Men1 deletion. 1001 TSS, transcriptional start site. (h) Venn diagram showing overlap between 1002 genes with reduction H3K4me3 in promoters by Men1 loss ( $n=6,469)$, genes 1003 with promoter bound by Menin $(n=7,364)$ and genes differentially expressed ( $n$ $1004=1,659)$ upon Men1 loss $(n=1,659)$. (i) Volcano plot show the top ten down1005 regulated genes upon Men1 deletion among the overlapped genes $(n=348)$ 1006 from $(h)$. 
a

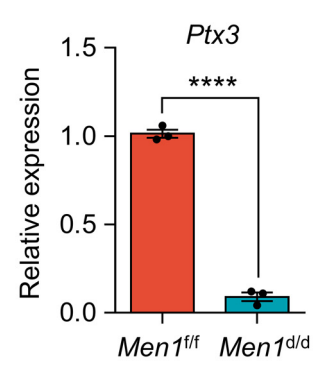

b

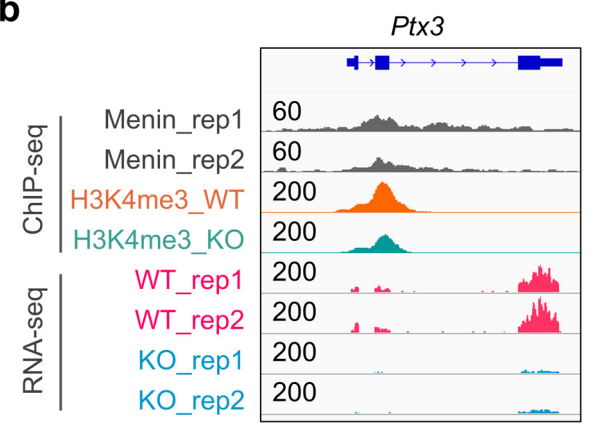

C

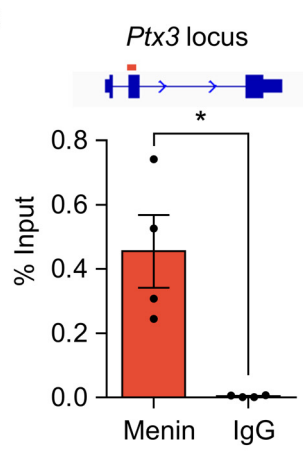

$\mathbf{f}$

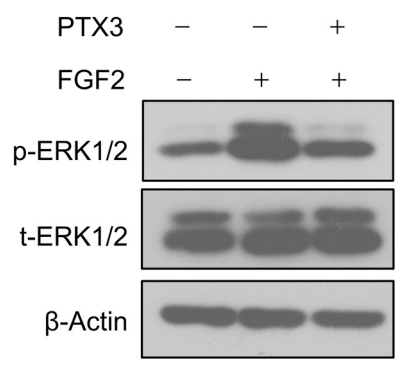

d

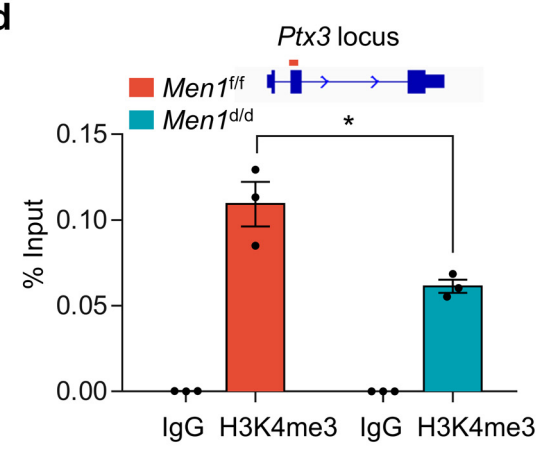

$\mathbf{h}$

g

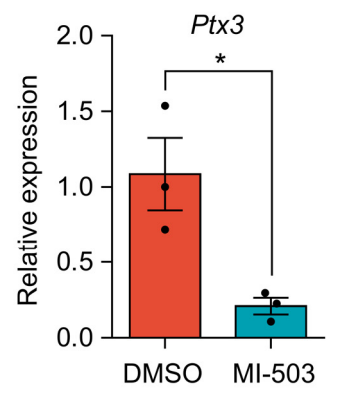

e

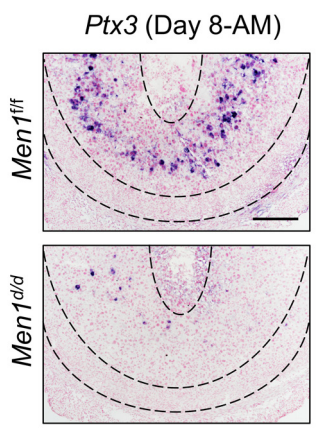

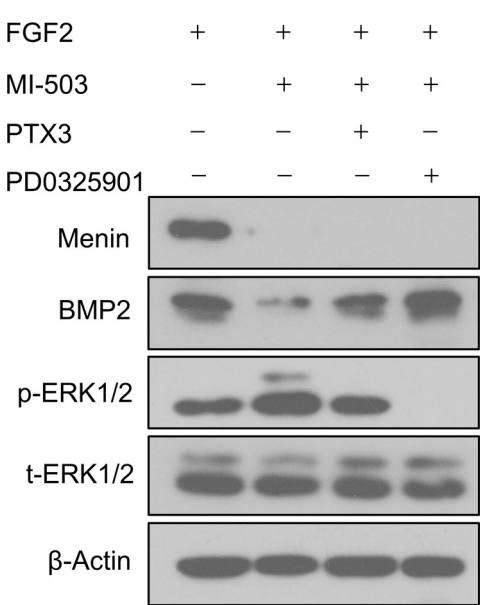

1008 Fig.7 Menin regulates the expression of BMP2 during decidualization by

1011 and indicated as the mean \pm SEM. Two-tailed unpaired Student's t test ${ }^{*} p<0.05$.

(b) Genome browser view of normalized ChIP-seq signals of Menin and

H3K4me3 at the Ptx3 promoter locus and RNA-seq tracks for Ptx3 in Men1//f 
1014 and Men $1^{\mathrm{d} / \mathrm{d}}$ decidual tissues. (c) Quantitative ChIP analysis of Menin in Ptx3 1015 promoter in uterine decidual tissue. Data represent the mean \pm SEM. Two-tailed 1016 unpaired Student's t test * $p=0.0282$. (d) Quantitative ChIP analysis of H3K4me3 1017 in Ptx3 promoter in Men $1^{\mathrm{f} / \mathrm{f}}$ and Men $1^{\mathrm{d} / \mathrm{d}}$ uterine decidual tissue. Data represent 1018 the mean \pm SEM. Two-tailed unpaired Student's t test ${ }^{*} p=0.0238$. (e) In situ 1019 hybridization of Ptx3 in Men $1^{\mathrm{f} / \mathrm{f}}$ and Men $1^{\mathrm{d} / \mathrm{d}}$ uteri on day 8 . Scale bar: $200 \mu \mathrm{m}$. 1020 (f) Immunoblotting analysis of the phosphorylation of ERK1/2 in mouse primary 1021 endometrial stromal cells treatment with FGF2 (20 ng/ml) in the absence or 1022 presence of PTX3 (100 ng/ml). Total ERK1/2 and $\beta$-Actin were used as loading 1023 controls. (g) Quantitative real-time PCR analysis of Ptx3 in primary mESC 1024 treated with DMSO or $\mathrm{MI}-503(2 \mu \mathrm{M})$ in vitro. The values are normalized to 1025 Gapdh and indicated as the mean \pm SEM. Two-tailed unpaired Student's t test $1026{ }^{*} p<0.05$. (h) Immunoblotting analysis of Menin, BMP2 and phosphorylated 1027 ERK1/2 after the addition of PTX3 (100 ng/ml) or PD0325901 $(5 \mu \mathrm{M})$ in mESC 1028 treatment with MI-503 $(2 \mu \mathrm{M})$ in the presence of FGF2 $(20 \mathrm{ng} / \mathrm{ml})$. Total ERK1/2 1029 and $\beta$-Actin were used as loading controls. 
a

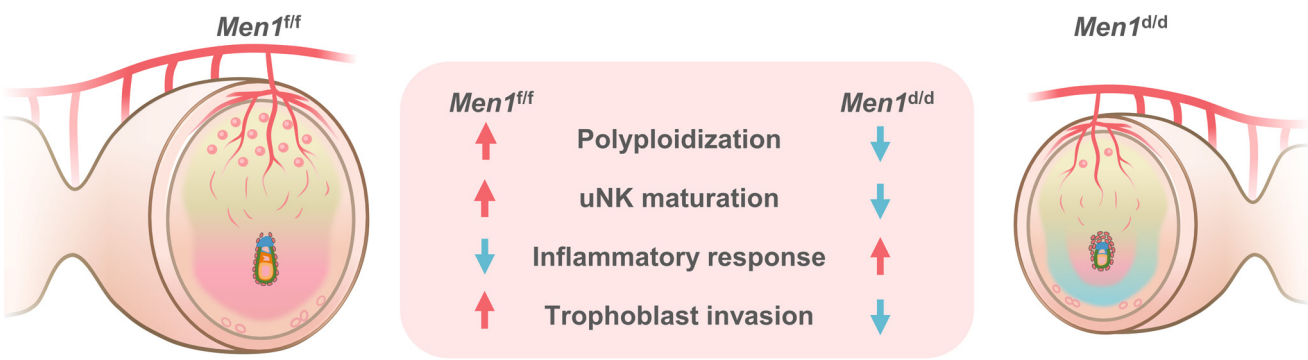

b
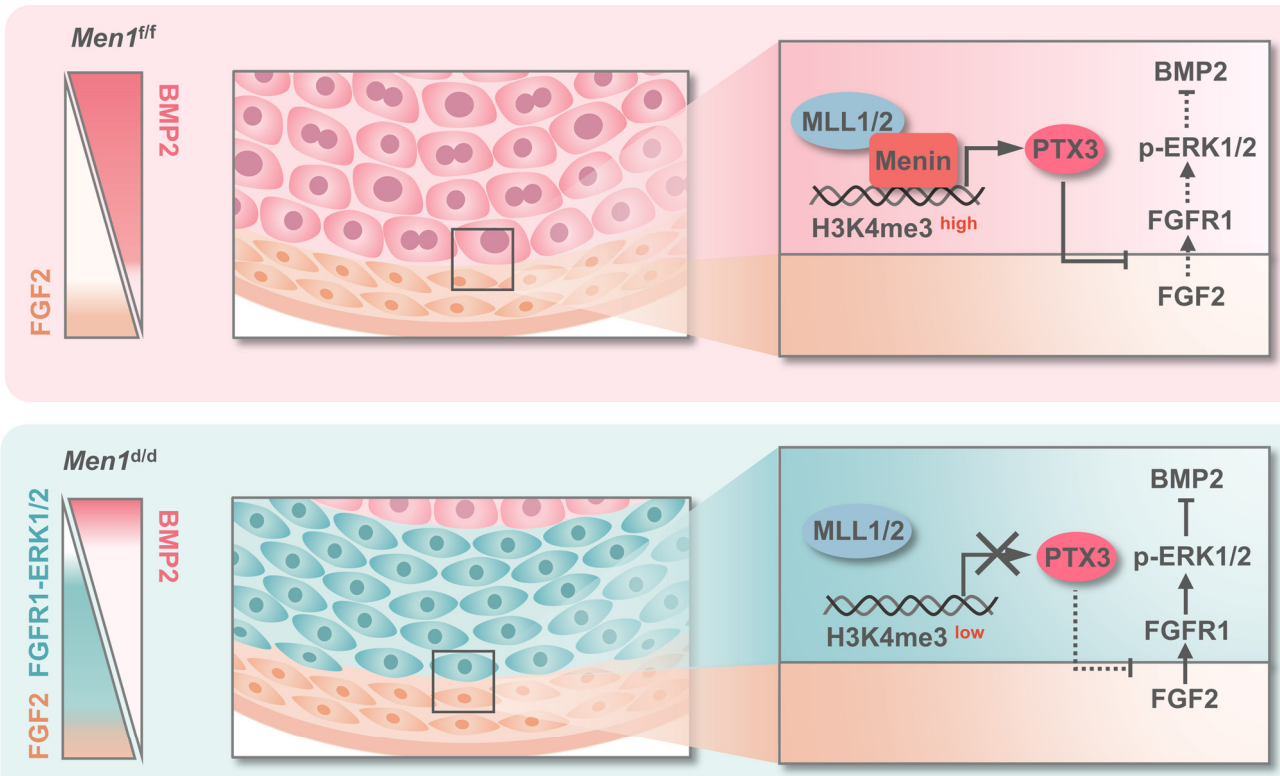

Differentiated decidual cell Insufficiently differentiated stromal cell Undifferentiated stromal cell

1031 Fig. 8 A proposed schematic diagram showing the function of uterine

1032 Men1 during decidualization. (a) Uterine deletion of Men1 leads to abnormal 1033 polyploidization of decidual cells in the SDZ, accompanied by impeded maturation of uNK cells, increased inflammatory response and shallow 1035 trophoblast invasion. (b) Menin positively regulates the expression of Ptx3 in a 1036 H3K4me3 dependent manner. PTX3, trapping FGF2 from undifferentiated 1037 stromal cells, ensures the expression of BMP2 in the SDZ by inhibiting the activation of FGF2-ERK1/2. 
a

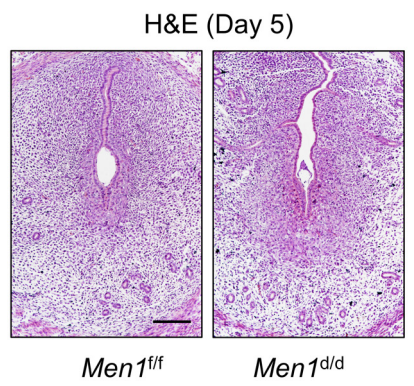

b

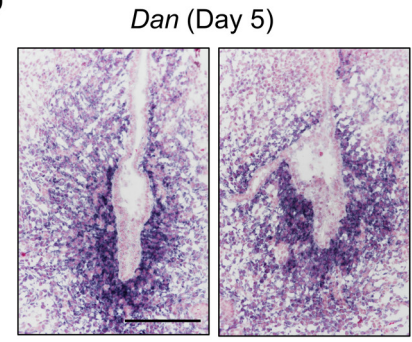

Men $1^{\mathrm{f} / \mathrm{f}}$

Men $1 \mathrm{~d} / \mathrm{d}$
C

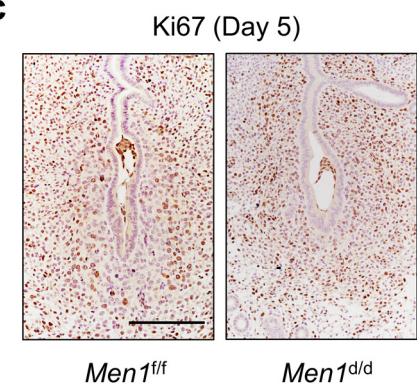

d

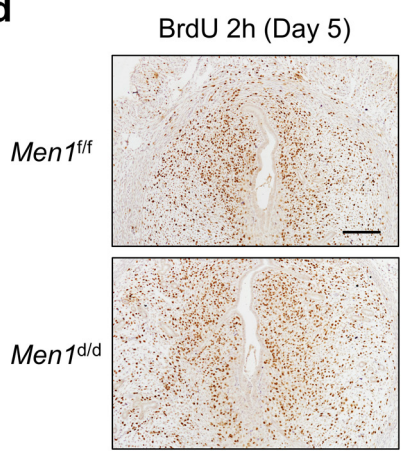

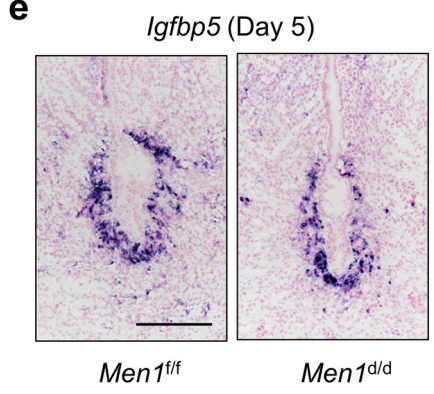

1040 Supplementary Fig. 1 Attachment reaction of blastocyst is comparable

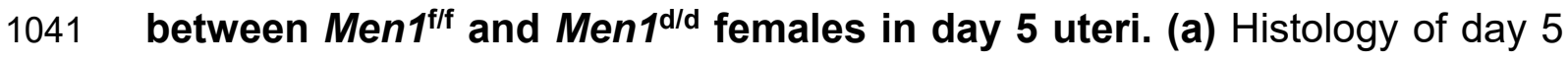
1042 implantation sites in $M e n 1^{\mathrm{f} / \mathrm{f}}$ and Men1 ${ }^{\mathrm{d} / \mathrm{d}}$ mice. Scale bar: $200 \mu \mathrm{m}$. (b) In situ 1043 hybridization of Dan in Men $1^{\text {f/f }}$ and Men $1^{\mathrm{d} / \mathrm{d}}$ uteri on day 5. Scale bar: $200 \mu \mathrm{m}$. 1044 (c, d) Immunohistochemistry of Ki67 and BrdU in Men1/f/f and Men1d/d 1045 implantation sites on day 5. Scale bar: $200 \mu \mathrm{m}$. (e) In situ hybridization of Igfbp5 1046 in Men ${ }^{\mathrm{flf}}$ and Men1 ${ }^{\mathrm{d} / \mathrm{d}}$ implantation sites on day 5. Scale bar: $200 \mu \mathrm{m}$. 
a

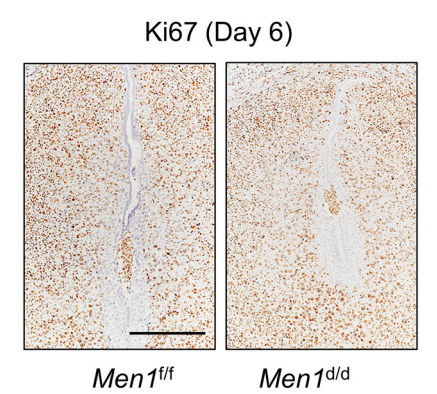

d

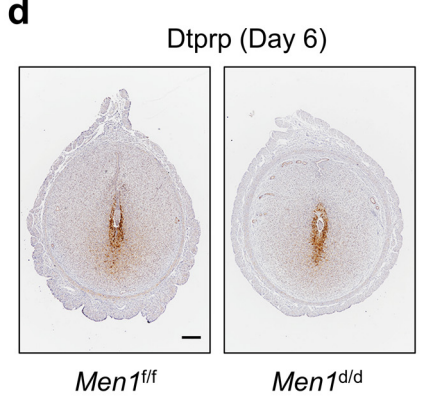

b

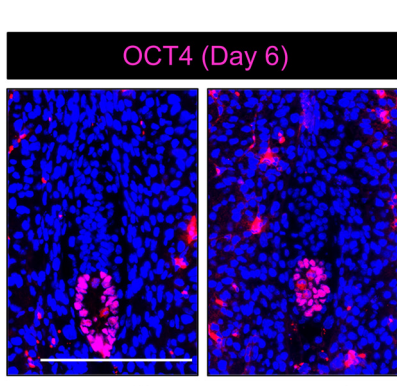

Men $1^{\text {f/f }}$

C

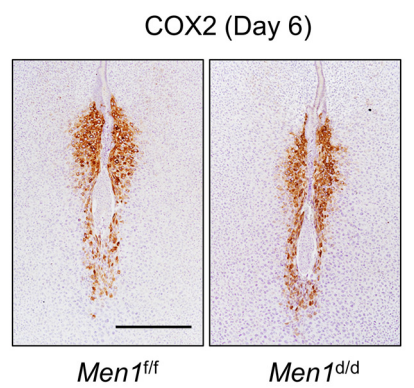

e

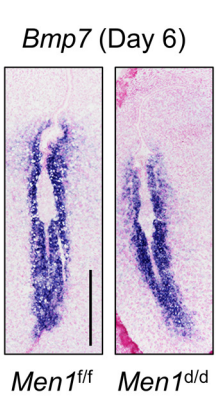

f

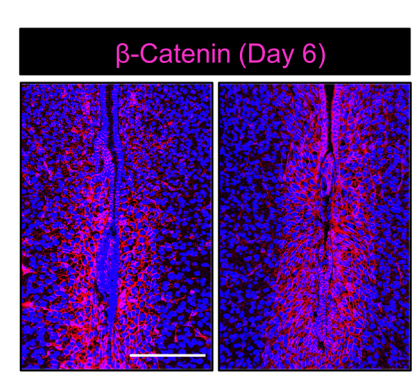

Ment $1^{\text {/f }}$

$M e n 1^{d / d}$ g

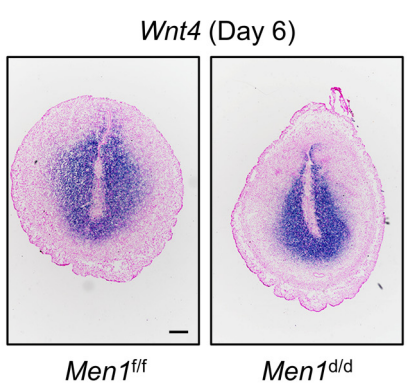

h

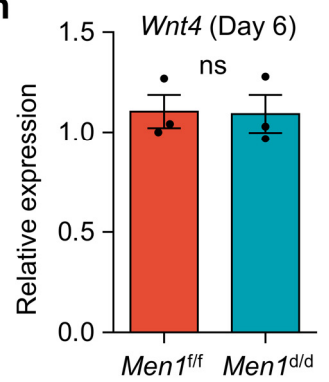

\section{Supplementary Fig. 2 Initiation of decidualization is comparable between}

Men $1^{\text {flf }}$ and Men $1^{\text {d/d }}$ uteri on day 6. (a) Immunohistochemistry of Ki67 in Men $1^{1 / f}$ and Men $1^{\mathrm{d} / \mathrm{d}}$ implantation sites on day 6. Scale bar: $200 \mu \mathrm{m}$. (b) Immunofluorescence analysis of OCT4 in Men $1^{\text {f/f }}$ and Men $1^{\mathrm{d} / \mathrm{d}}$ implantation sites on day 6. Scale bar: $200 \mu \mathrm{m}$. (c, d) Immunohistochemistry of COX2 and Dtprp in $M e n 1^{\text {f/f }}$ and $M e n 1^{\mathrm{d} / \mathrm{d}}$ implantation sites on day 6. Scale bar: $200 \mu \mathrm{m}$. (e) In situ hybridization of $B m p 7$ in $M e n 1^{\mathrm{fff}}$ and Men1 ${ }^{\mathrm{d} / \mathrm{d}}$ implantation sites on day 6. Scale bar: $200 \mu \mathrm{m}$. (f) Immunofluorescence analysis of $\beta$-Catenin in Men1/ff and Men $1^{\text {d/d }}$ implantation sites on day 6. Scale bar: $200 \mu \mathrm{m}$. (g) In situ hybridization 


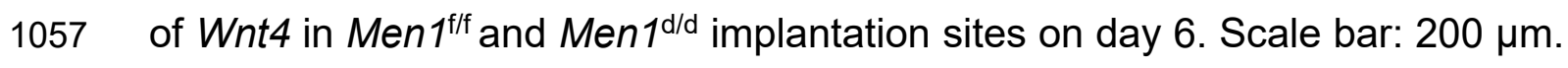

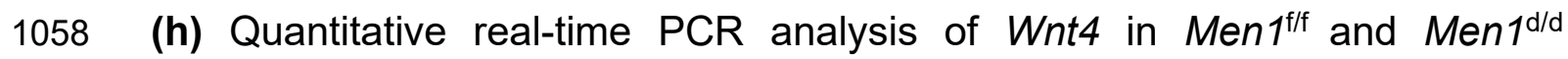
1059 implantation sites on day 6. The values are normalized to Gapdh and indicated 1060 as the mean \pm SEM. Two-tailed unpaired Student's $t$ test. ns, not significant. 
a

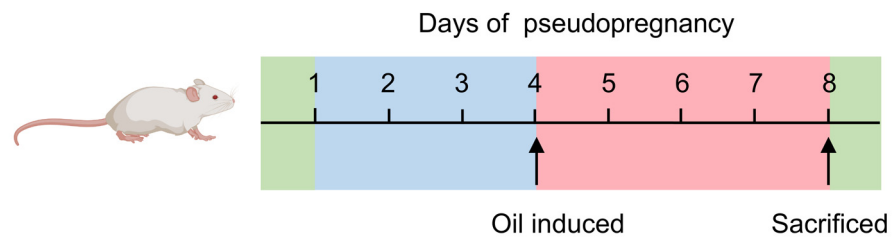

b

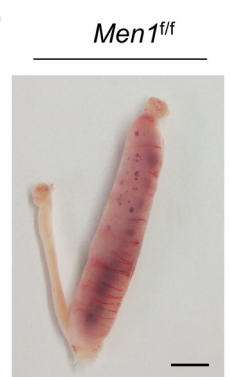

Men1/d/

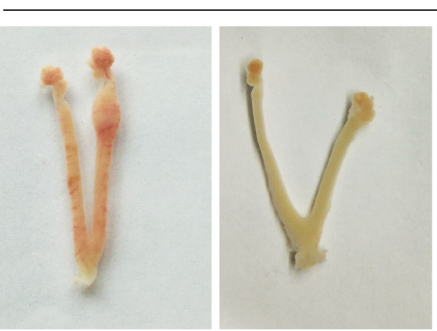

C

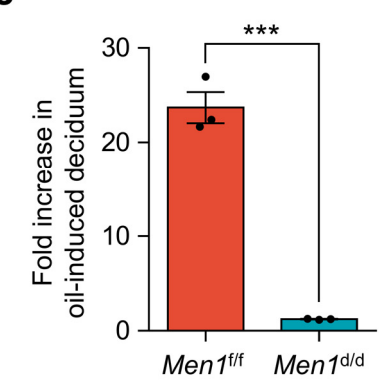

Supplementary Fig. 3 Loss of Men1 impairs uterine decidualization in oil-

induced model. (a) Schematic diagram of surgical regimen used to induce

1064 decidual response. Mice were treated with oil $(25 \mu \mathrm{l})$ in one uterine horn on day

4 of pseudopregnancy. Uteri were collected on day 8. (b) Gross morphology of

1066 the decidual response in Men $1^{\mathrm{f} / \mathrm{f}}$ and $M e n 1^{\mathrm{d} / \mathrm{d}}$ uteri on day 8 of pseudopregnancy.

1067 Scale bar: $5 \mathrm{~mm}$. (c) Ratio of the decidual horn to the control horn weight of

1068 Men $^{\mathrm{f} / \mathrm{f}}$ and Men $1^{\mathrm{d} / \mathrm{d}}$ uteri on day 8 of pseudopregnancy. Data represent the 1069 mean \pm SEM. Two-tailed unpaired Student's t test ${ }^{* * *} p<0.001$ 
a

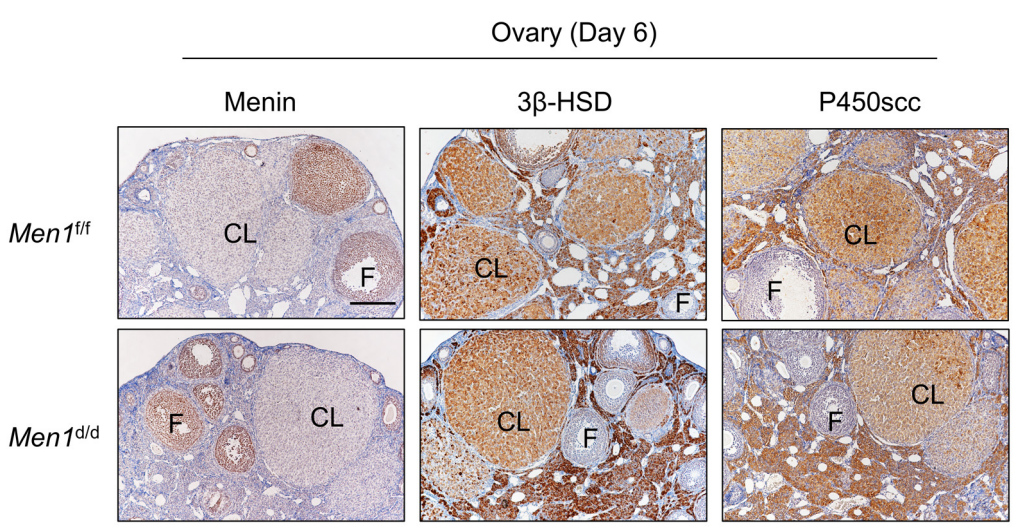

b Day 6

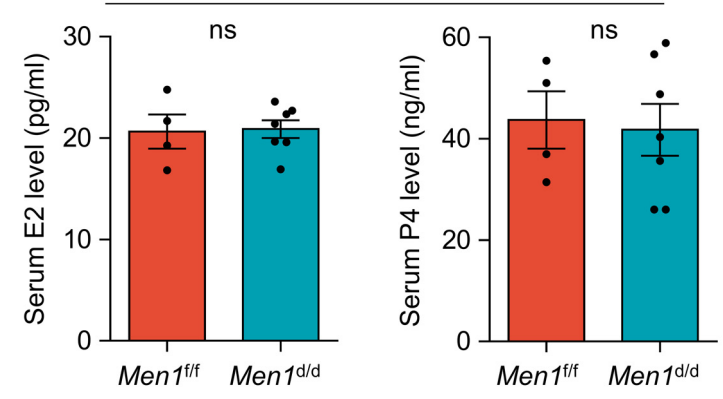

1070

1071 Supplementary Fig. 4 Ovarian steroid hormone secretion is comparable

1072 between Men1 $^{\mathrm{flf}}$ and Men1//d mice. (a) Immunohistochemistry staining of

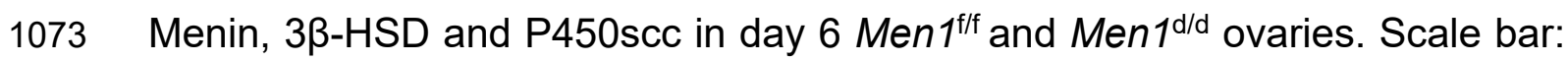

$1074200 \mu m$. CL, corpus luteum; F, follicle. (b) Serum estradiol-17 $($ E2) and

1075 progesterone (P4) levels in $M e n 1^{\mathrm{f} / \mathrm{f}}$ and $M e n 1^{\mathrm{d} / \mathrm{d}}$ mice on day 6 . Data represent

1076 the mean \pm SEM. Two-tailed unpaired Student's $t$ test. ns, not significant. 
a

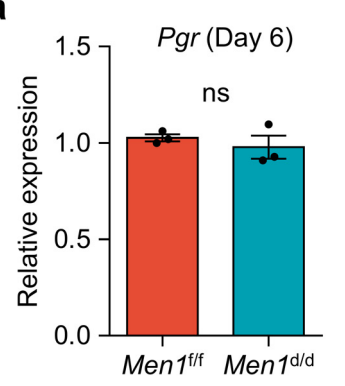

b

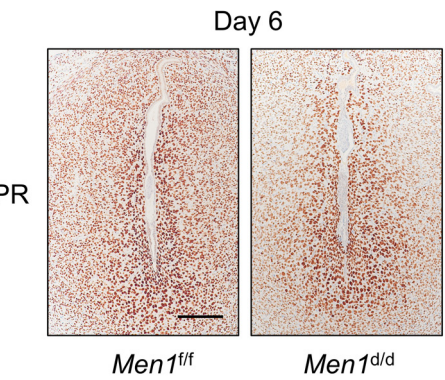

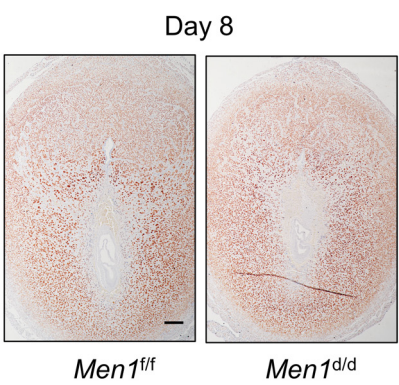

Hand2

d

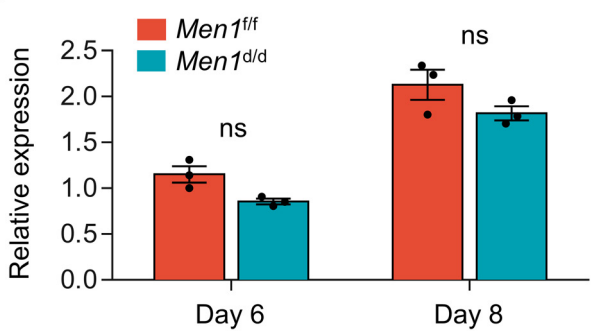

$\mathbf{f}$

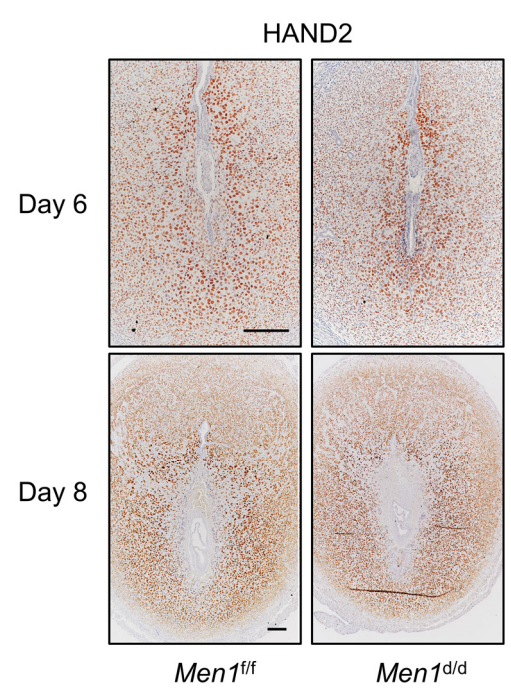

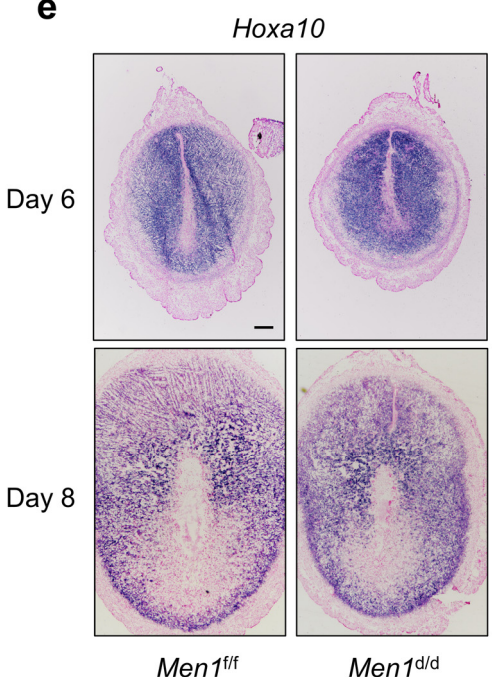

e

C

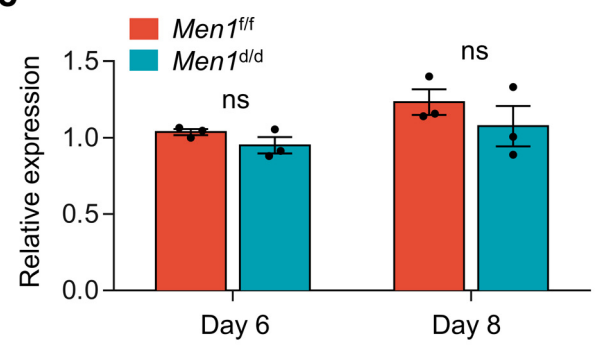

f
1078

1079

1080 1081 and indicated as the mean \pm SEM. Two-tailed unpaired Student's $t$ test. ns, not

1082

1083

1084

progesterone signaling pathway. (a) Quantitative real-time PCR analysis of $P g r$ in $M e n 1^{f / f}$ and Men $1^{d / d}$ uteri on day 6. The values are normalized to Gapdh significant. (b) Immunohistochemistry of PR in the implantation sites of $M e n 1^{\text {f/f }}$ and Men $1^{\mathrm{d} / \mathrm{d}}$ mice on day 6 and day 8 of pregnancy. Scale bars: $200 \mu \mathrm{m}$. (c, d) Quantitative real-time PCR analysis of Hand2 and Hoxa10 in Men1/ff and

Supplementary Fig. 5 Uterine deficiency of Men1 has no adverse effect on 
1085 Men $1^{\mathrm{d} / \mathrm{d}}$ uteri on day 6 and day 8 . The values are normalized to Gapdh and 1086 indicated as the mean \pm SEM. Two-tailed unpaired Student's $t$ test. ns, not

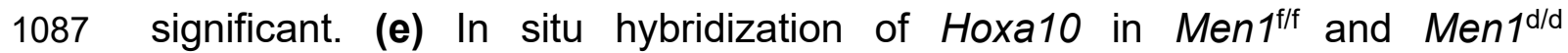
1088 implantation sites on day 6 and day 8 . Scale bar: $200 \mu \mathrm{m}$. (f) 1089 Immunohistochemistry of HAND2 in Men $1^{\text {f/f }}$ and Men $1^{\mathrm{d} / \mathrm{d}}$ implantation sites on 1090 day 6 and day 8 . Scale bars: $200 \mu \mathrm{m}$. 
a

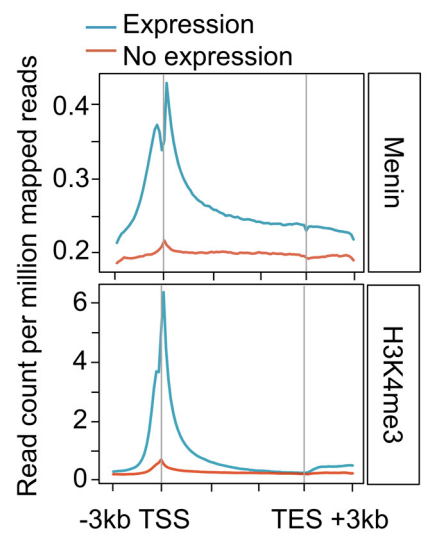

C

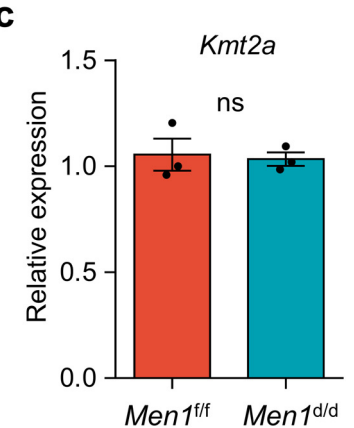

b

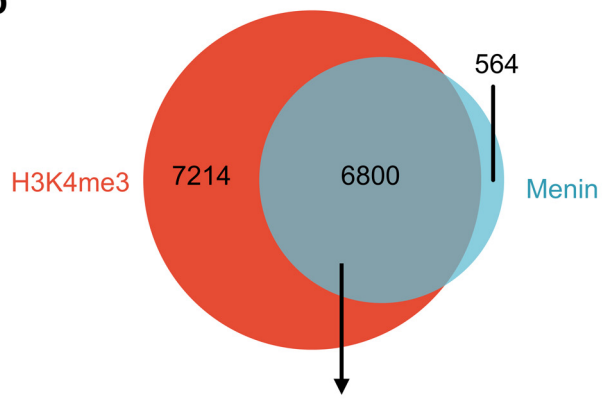

Genes with promoter enrichment with both Menin and H3K4me3

e
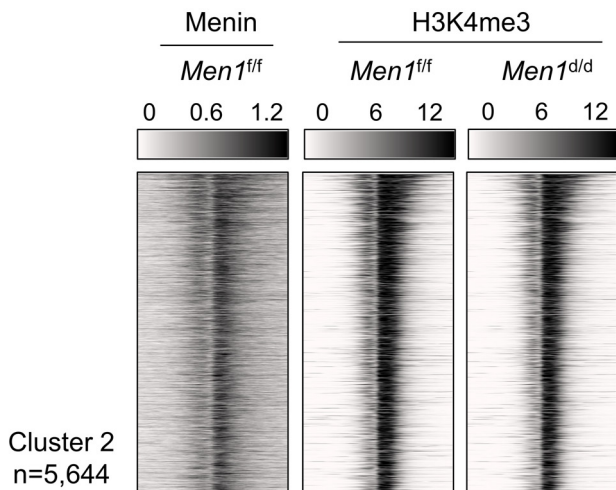

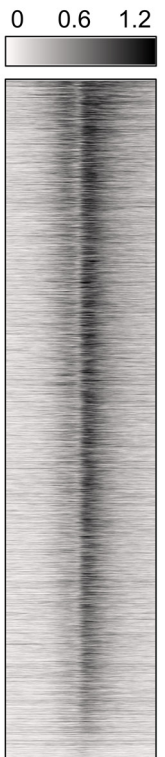

TSS

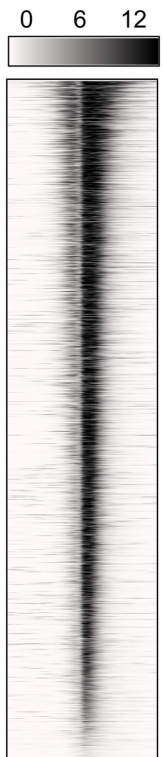

TSS $\begin{array}{lll}0 & 6 & 12\end{array}$

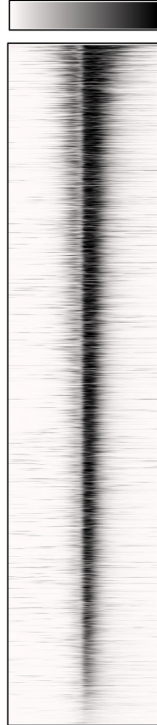

1091

d

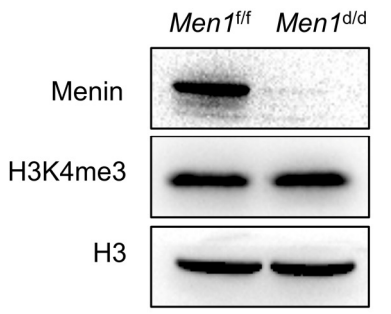

\section{Supplementary Fig. 6 Uterine specific deletion of Men1 does not affect the}

global H3K4me3 level. (a) Menin and H3K4me3 ChIP-seq signal density in

the genome. (b) Venn diagram of genes with promoter enriched by H3K4me3 and Menin. (c) Quantitative real-time PCR analysis of $K m t 2 a$ and $K m t 2 b$ mRNA levels in $M e n 1^{\mathrm{f} / \mathrm{f}}$ and $M e n 1^{\mathrm{d} / \mathrm{d}}$ implantation sites on day 8 . The values are

1097 normalized to Gapdh and indicated as the mean \pm SEM. Two-tailed unpaired

1098 Student's t test. ns, not significant. (d) Immunoblotting analysis of H3K4me3 in $1099 M^{\mathrm{f} / \mathrm{f}}$ and Men $1^{\mathrm{d} / \mathrm{d}}$ decidual tissues on day $8 . \mathrm{H} 3$ was used as loading controls. 
1100 (e) Coverage profiles for Menin and H3K4me3. Heatmaps are centered at TSS.

11015,644 genes in cluster 2 have no significant difference of $\mathrm{H} 3 \mathrm{~K} 4 \mathrm{me} 3$ modification 1102 following Men1 deletion. TSS, transcriptional start site. 
a

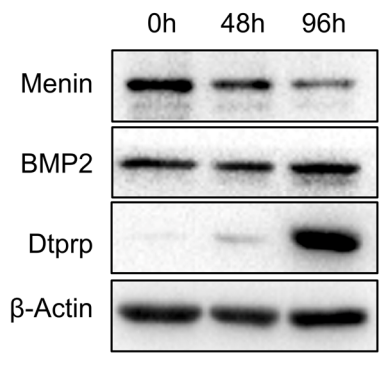

C

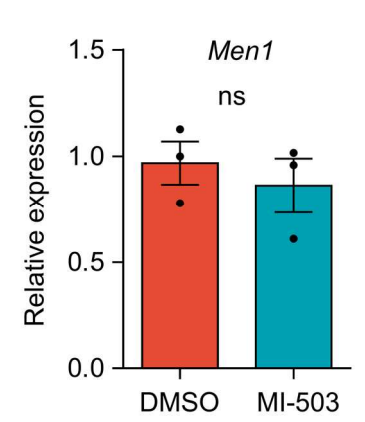

b

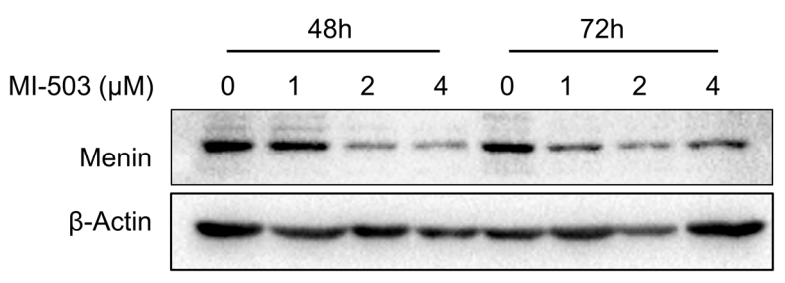

e

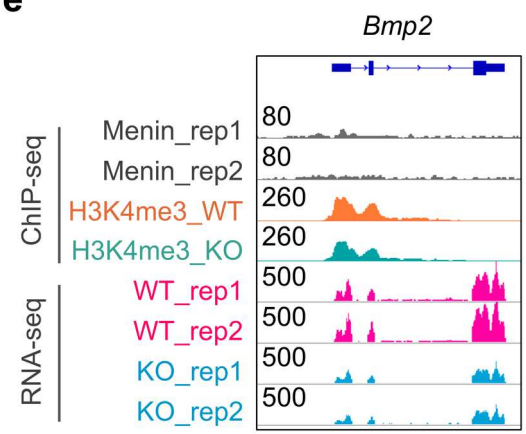

1103 d

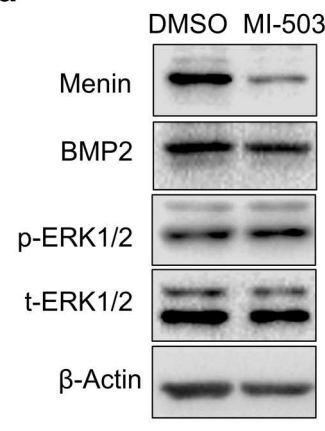

Supplementary Fig. 7 MI-503 Treatment has no effect on the expression of

Bmp2 in the absence of Fgf2. (a) Immunoblotting analysis of Menin, BMP2 and Dtprp expression for mouse primary endometrial stromal cells during in vitro decidualization. $\beta$-Actin was used as loading control. (b) Immunoblotting analysis of Menin expression in the presence of $0,1,2$, or $4 \mu \mathrm{M} \mathrm{MI-503} \mathrm{in} \mathrm{mESC.}$ $\beta$-Actin was used as loading control. (c) Quantitative real-time PCR analysis of Men1 in mESC during in vitro decidualization with or without treatment of $2 \mu \mathrm{M}$ MI-503 for $72 \mathrm{~h}$. The values are normalized to Gapdh and indicated as the mean \pm SEM. Two-tailed unpaired Student's $t$ test. ns, not significant. (d) Immunoblotting analysis of Menin, BMP2 and p-ERK1/2 in mESC treatment with Ml-503 $(2 \mu \mathrm{M})$ for $72 \mathrm{~h}$ during in vitro decidualization. Total ERK1/2 and $\beta$ Actin were used as loading controls. (e) Genome browser view of normalized ChIP-seq signals of Menin and H3K4me3 at the Bmp2 promoter locus and RNA-seq tracks for Bmp2 in Men1 ${ }^{\mathrm{flf}}$ and Men $1^{\mathrm{d} / \mathrm{d}}$ decidual tissues. 
1118 Supplementary Table 1: Antibody information

\begin{tabular}{|c|c|c|}
\hline Antibodies & Company & Catalog No. \\
\hline Menin & Bethyl & A300-105A \\
\hline Dtprp & homemade & N/A \\
\hline p27 & Abcam & ab32034 \\
\hline cox2 & Santa Cruz & sc-1746 \\
\hline Ki67 & Abcam & $a b 15580$ \\
\hline PR & CST & 8757 \\
\hline P450-scc & Santa Cruz & sc-18043 \\
\hline $3 \beta-H S D$ & Santa Cruz & sc-30820 \\
\hline HAND2 & Santa Cruz & sc-9409 \\
\hline PL1 & Santa Cruz & sc-34713 \\
\hline $\mathrm{pH} 3$ & CST & 9701 \\
\hline ОСТ4 & CST & 2840 \\
\hline$\beta$-Catenin & Epitomics & $1247-1$ \\
\hline H3K27me3 & CST & 9733 \\
\hline BrdU & Abcam & $a b 6326$ \\
\hline PCNA & Epitomics & $2714-1$ \\
\hline p-ERK1/2 & CST & 4370 \\
\hline ERK1/2 & CST & 4695 \\
\hline BMP2 & Abcam & ab32034 \\
\hline p-SMAD1/5/8 & CST & 9516 \\
\hline
\end{tabular}




\begin{tabular}{|l|l|l|}
\hline SMAD1/5/8 & CST & 9743 \\
\hline H3K4me3 & Abcam & ab8580 \\
\hline H3 & Abmart & TD6932 \\
\hline B-Actin & Bioworld & AP0060 \\
\hline
\end{tabular}

1120 Supplementary Table 2. Primer list.

1121 Quantitative real time PCR primer

\begin{tabular}{|c|c|c|}
\hline Gene & Forward primer (5'-3') & Reverse primer (5'-3') \\
\hline Men1 & СССАСТСАСССТТТАТСА & CGGCAGTAGTTGTAGTCT \\
\hline Gapdh & TGGCAAAGTGGAGATTGTTGCC & AAGATGGTGATGGGCTTCCCG \\
\hline Wnt4 & AGGAGTGCCAATACCAGT & GCTGAAGAGATGGCGTATAC \\
\hline Ptgs2 & GTCTGGTGCCTGGTCTGATGAT & GTGGTAACCGCTCAGGTGTTG \\
\hline Pgr & АCCTGATCTAATCCTAAATGA & ATTGTGTTAAGAAGTAGTAAGAC \\
\hline Hoxa10 & GGCAGTTCCAAAGGCGAAAA & CAAAAAAAGCCAGAACAAAC \\
\hline Hand2 & TCGGTTATCTAGTGCTGTC & ATACTTACAATGTTTACACCTTCA \\
\hline Angpt1 & TTCTTCGCTGCCATTCTGACTC & CGTTGGTGTTGTACTGCTCTG \\
\hline Angpt2 & ACGGTCAACAACTCGCTCCT & TTCCGCACAGTCTCTGAAGGT \\
\hline Cdkn1b & TCAAACGTGAGAGTGTCTAACG & CCGGGCCGAAGAGATTTCTG \\
\hline Fgfr1 & ACCTCACCGCTCTACCTGGA & TCTGGCTATGGAAGTCGCTCTT \\
\hline Fgf2 & AGAACGGCGGCTTCTTCCT & TGGCACACACTCCCTTGATAGA \\
\hline Bmp2 & GATCTGTACCGCAGGCACTCA & AGTTCCTCCACGGCTTCTTCG \\
\hline Id1 & CGAGGTGGTACTTGGTCTGT & CCTTGAGGCGTGAGTAGCA \\
\hline
\end{tabular}




\begin{tabular}{|c|c|c|}
\hline Ptx3 & AGCGTGCATCCTGTGAGACCA & TCCTTTCCACCCACCACCAACA \\
\hline$K m t 2 a$ & GAGCAGCCATCGCAGAAGGA & GAGCCAGAGCATCAGAGGAGAG \\
\hline$K m t 2 b$ & GCAAGAGGAAGAGGAGGAGACT & GCTGGAGGTGGAGGAGATGTT \\
\hline
\end{tabular}

1123 ChIP assay primers

\begin{tabular}{|c|c|c|}
\hline Gene & Forward primer (5'-3') & Reverse primer (5'-3') \\
\hline Ptx3 & CCAGGACAAGCTGATAACACTT & GCATCTGCGAGTTCTCCAG \\
\hline
\end{tabular}

